\title{
Tool for analysis of multichannel analysis of surface waves (MASW) field data and evaluation of shear wave velocity profiles of soils
}

\author{
Elin Asta Olafsdottir, Sigurdur Erlingsson, and Bjarni Bessason
}

\begin{abstract}
Multichannel analysis of surface waves (MASW) is a fast, low-cost, and environmentally friendly technique to estimate shear wave velocity profiles of soil sites. This paper introduces a new open-source software, MASWaves, for processing and analysing multichannel surface wave records using the MASW method. The software consists of two main parts: a dispersion analysis tool (MASWaves Dispersion) and an inversion analysis tool (MASWaves Inversion). The performance of the dispersion analysis tool is validated by comparison with results obtained by the Geopsy software package. Verification of the inversion analysis tool is carried out by comparison with results obtained by the software WinSASW and theoretical dispersion curves presented in the literature. Results of MASW field tests conducted at three sites in south Iceland are presented to demonstrate the performance and robustness of the new software. The soils at the three test sites ranged from loose sand to cemented silty sand. In addition, at one site, the results of existing spectral analysis of surface waves (SASW) measurements were compared with the results obtained by MASWaves.
\end{abstract}

Key words: multichannel analysis of surface waves (MASW), dispersion analysis, inversion analysis, open-source software, shear wave velocity.

Résumé : L’analyse multicanal des ondes de surface ("MASW") est un moyen technique rapide, peu coûteux et respectueux de l'environnement pour estimer les profils de vitesse des ondes de cisaillement de sites de sols. L'article présente un nouveau logiciel à source ouverte, MASWaves, pour le traitement et l'analyse d'enregistrements des ondes de surface multicanal à l'aide de la méthode MASW. Le logiciel se compose de deux parties principales; un outil d'analyse de la dispersion (la dispersion MASWaves) et un outil d'analyse d'inversion (l'inversion MASWaves). La performance de l'outil d'analyse de la dispersion est validée par la comparaison aux résultats obtenus par le logiciel Geopsy. La vérification de l'outil d'analyse d'inversion est effectuée par rapport aux résultats obtenus par le logiciel WinSASW et les courbes de dispersion théoriques présentés dans la littérature. Les résultats des essais sur le terrain de MASW effectués dans trois sites dans le sud de l'Islande sont présentés afin de démontrer les performances et la robustesse de ce nouveau logiciel. Les sols à l'essai aux trois sites allant de sable lâche au sable limoneux cimenté. De plus, sur un site, les résultats de mesures de l'analyse spectrale des ondes de surface ("SASW ») ont été comparés aux résultats obtenus par MASWaves. [Traduit par la Rédaction]

Mots-clés : analyse multicanal des ondes de surface (MASW), analyse de la dispersion, analyse de l'inversion, logiciels à source ouverte, vitesse des ondes de cisaillement.

\section{Introduction}

Knowledge of the geotechnical properties of subsoil sites is essential in various civil engineering projects. The shear wave velocity of the top-most soil layers is a key parameter in this sense. The small-strain shear modulus of individual soil layers $\left(G_{\max }\right)$ is directly proportional to the square of their characteristic shear wave velocity. Furthermore, the shear wave velocity is vital in assessments of both liquefaction potential and soil amplification and for seismic site classification (Kramer 1996). For instance, the time-average shear wave velocity of the uppermost $30 \mathrm{~m}\left(V_{\mathrm{S}, 30}\right)$ is used to account for the effects of the local ground conditions on the seismic action when site-specific design spectra are defined according to Eurocode 8 (CEN 2004).

Several in situ methods can be applied to estimate the shear wave velocity profile of near-surface materials (Gazetas 1991;
Kramer 1996). Among these are methods that require access to a drilled borehole such as down-hole and cross-hole seismic surveys, methods where the resistance of soil to penetration is measured as in the standard penetration test and the cone penetration test and surface wave analysis methods. Surface wave analysis methods are based on the dispersive properties of surface waves propagating through a heterogeneous medium (Aki and Richards 1980). In published studies, the main focus has been on the analysis of Rayleigh waves as they are both easy to generate and to detect on the ground surface using low-frequency receivers (Socco et al. 2010). Compared to other available methods, surface wave analysis methods are low-cost, as well as being noninvasive and environmentally friendly because they neither require heavy machinery nor leave lasting marks on the surface of the test site. This makes the application of surface wave analysis methods for estimating the shear wave velocity profile of subsoil sites very appealing.

Received 2 June 2016. Accepted 23 May 2017.

E.A. Olafsdottir, S. Erlingsson, and B. Bessason. Faculty of Civil and Environmental Engineering, University of Iceland, Hjardarhagi 2-6, IS-107 Reykjavik, Iceland.

Corresponding author: Elin Asta Olafsdottir (email: eao4@hi.is).

Copyright remains with the author(s) or their institution(s). This work is licensed under a Creative Commons Attribution 4.0 International License (CC BY 4.0), which permits unrestricted use, distribution, and reproduction in any medium, provided the original author(s) and source are credited. 
The basis of most surface wave analysis methods is accurate determination of the frequency-dependent phase velocity of fundamental-mode Rayleigh waves (Park et al. 1999), i.e., the experimental fundamental-mode dispersion curve. Apart from being a function of frequency, the Rayleigh wave phase velocity is related to several groups of soil properties, most importantly the shear wave velocity (Xia et al. 1999). Hence, by inversion of the experimental dispersion curve, the shear wave velocity profile for the test site can be determined.

Several types of surface wave analysis methods can be applied to estimate the shear wave velocity profile of the top-most soil layers. Among them are spectral analysis of surface waves (SASW) and multichannel analysis of surface waves (MASW). The SASW method has been used since the early 1980s and is based on analysis of surface wave records acquired by multiple pairs of receivers (Nazarian et al. 1983). The MASW method is a newer and more advanced technique, developed to overcome some of the weaknesses of the SASW method (Park et al. 1999). In recent years, the MASW method has attracted increasingly more attention and has become one of the key surface wave analysis methods to determine near-surface shear wave velocity profiles for applications in civil engineering (Xia 2014). The main advantages of MASW, as compared to the SASW method, include a more efficient dataacquisition routine in the field, faster and less labour-consuming data processing procedures, and improved identification and elimination of noise from recorded data (Park et al. 1999; Xia et al. 2002). Reduction of noise leads to a more accurate experimental dispersion curve and ultimately a more precise shear wave velocity profile. Furthermore, the MASW method makes it possible to observe and extract higher-mode dispersion curves based on the recorded surface wave data (Xia et al. 2003). Finally, it is possible to map deeper shear wave velocity profiles when using the same impact load. The observed difference between results obtained by MASW and direct borehole measurements has been estimated as approximately $15 \%$ or less and random (Xia et al. 2002).

The maximum depth of investigation in a MASW survey varies with site, the configuration of the measurement profile, the natural frequency of the receivers, and the type of seismic source that is used (Park and Carnevale 2010; Park et al. 2002, 2007). The investigation depth is determined by the longest Rayleigh wave wavelength that is retrieved. A commonly adopted empirical criterion (Park and Carnevale 2010) is that

$$
z_{\max } \approx 0.5 \lambda_{\max }
$$

where $z_{\max }$ is the maximum investigation depth and $\lambda_{\max }$ is the longest wavelength.

The investigation depth that can be achieved by a MASW survey is usually a few tens of metres, assuming that the surface waves are generated by a reasonably heavy impulsive (active) source, e.g., a sledgehammer (Park et al. 2005, 2007). Surface waves that are generated by natural sources and (or) man-made activities have lower frequencies (longer wavelengths) than waves generated by impact loads. Multiple techniques have been applied for analysis of ambient noise (passive-source) vibrations acquired by a linear receiver array (e.g., Louie 2001; Park and Miller 2008), a two-dimensional array (e.g., Asten 2006; Di Giulio et al. 2006; Garofalo et al. 2016; Wathelet et al. 2008) or a single station (e.g., Gouveia et al. 2016; Hobiger et al. 2009, 2013). By combining results of active-source and passive-source surveys, an increased range in investigation depth can be obtained.

This paper introduces the first version of a new open-source software, MASWaves (Multichannel Analysis of Surface Waves for assessing shear wave velocity profiles of soils), for application of the MASW method, developed at the Faculty of Civil and Environmental Engineering, University of Iceland (Olafsdottir 2016). MASWaves contains two fundamental parts: a tool for processing of MASW field data and evaluation of experimental dispersion curves (MASWaves Dispersion) and a tool for computation of theoretical dispersion curves and evaluation of shear wave velocity profiles by inversion of the experimental data (MASWaves Inversion). Verification of MASWaves Dispersion is carried out by comparison with results obtained by using the open-source software Geopsy. Theoretical dispersion curves computed by MASWaves Inversion were compared with theoretical fundamental-mode curves obtained by using the software WinSASW (version 1.2; UTAustin 1992) as well as fundamental- and first higher-mode dispersion curves presented by Tokimatsu et al. (1992) and Tokimatsu (1997).

Results of MASW field tests conducted at three test sites in south Iceland are presented to demonstrate the performance and robustness of the new software. Moreover, at one test site, the results of the MASW analysis were compared with results of SASW measurements carried out previously at the site.

The software MASWaves, which is written in Matlab, can be downloaded free of charge at masw.hi.is, along with a user guide and sample data.

\section{Multichannel analysis of surface waves}

The MASW method is divided into three main steps: field measurements, dispersion analysis, and inversion analysis (Park et al. 1999). The software MASWaves is designed to perform the dispersion analysis and the inversion analysis. A single multichannel surface wave record is sufficient to carry out the analysis. The main data acquisition and computational steps are illustrated in Fig. 1.

For data acquisition, low-frequency receivers (geophones) are lined up on the surface of the test site (Fig. 1a). A wave is generated by an impulsive source that is applied at one end of the measurement profile and the geophones record the resulting wave propagation as a function of time (Fig. $1 b$ ). The number of receivers is denoted by $N$. An illustration of a typical MASW measurement profile is provided in Fig. 2. The distance from the impact load point to the first receiver in the geophone line is referred to as the source offset and denoted by $x_{1}$ and the receiver spacing is $\mathrm{dx}$. Hence, the length of the receiver spread is $L=(N-1) \mathrm{dx}$ and the total length of the measurement profile is $L_{T}=x_{1}+(N-1) d x$.

In the dispersion analysis, dispersion curves are extracted from the acquired surface wave data. Several different methods can be used. Transform-based methods, in which the acquired time series are transformed from the space-time domain into a different domain, are most commonly used for active-source surveys (Socco et al. 2010), i.e., the frequency-wave number $(f-k)$ transform (Yilmaz 1987), the slowness-frequency ( $p-\omega)$ transform (McMechan and Yedlin 1981), and the phase shift method (Park et al. 1998). Each transform provides an image of the dispersive properties of the recorded surface waves (Fig. 1c) from which the Rayleigh wave dispersion curve(s) are identified and extracted based on the spectral maxima (Fig. 1d). Dal Moro et al. (2003) compared the effectiveness of the phase shift method, the $f-k$ transform, and the $p-\omega$ transform to determine Rayleigh wave dispersion curves for nearsurface applications in unconsolidated settlements. They concluded that the phase shift method, which was used in this work, is a robust and computationally efficient method that provides accurate fundamental-mode phase velocities even when data from as little as four geophones are available.

The inversion analysis involves obtaining a shear wave velocity profile by backcalculation of the experimental dispersion curve. A theoretical dispersion curve is computed based on an assumed set of model parameters, including an assumed shear wave velocity profile for the test site. Different sets of parameters are inserted into the theoretical model in an iterative way in search of the theoretical dispersion curve that is the most consistent with the measured curve (Fig. 1e). The shear wave velocity profile that results in a theoretical dispersion curve that fits the experimental 
Fig. 1. Overview of the MASW method: $(a, b)$ field measurements; $(c, d)$ dispersion analysis; $(e, f)$ inversion analysis. [Colour online.]

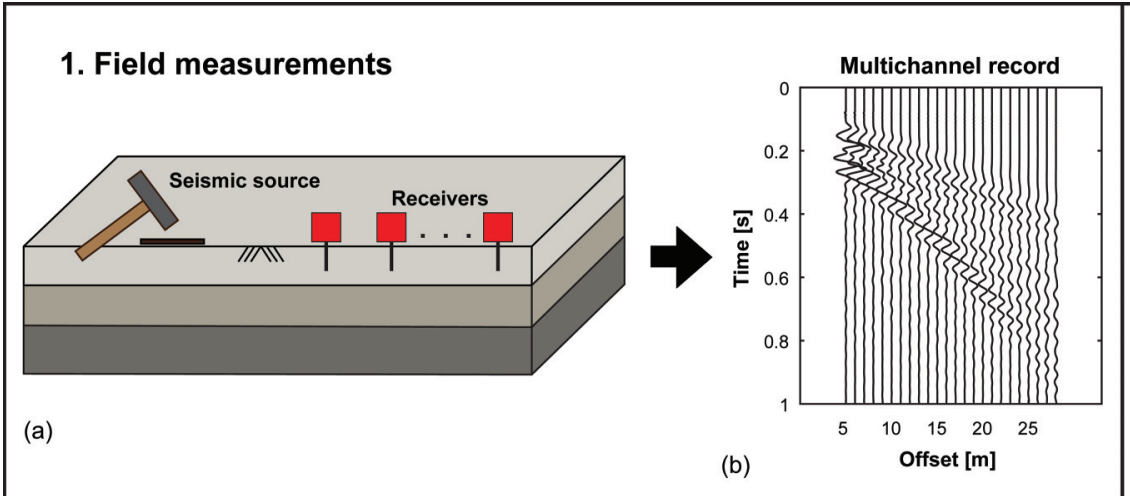

\section{Inversion analysis}

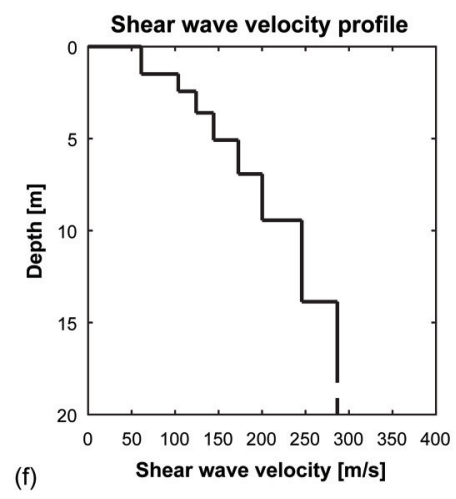

Experimental and theoretical dispersion curves

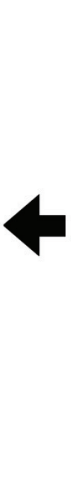

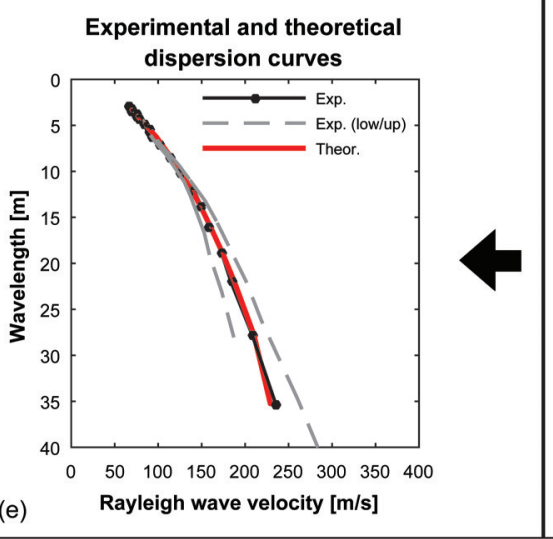

\section{Dispersion analysis}

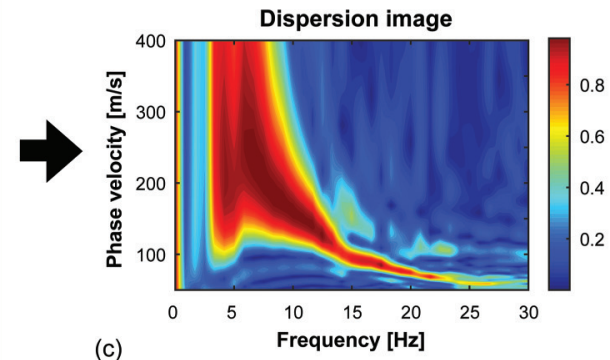

(c)

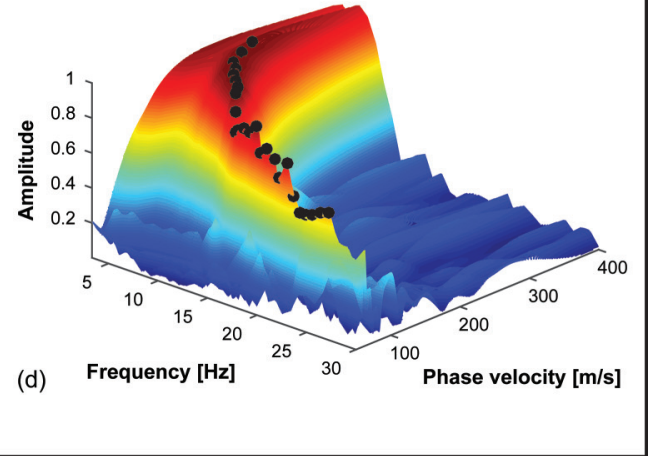

Fig. 2. Typical MASW measurement profile with 24 receivers. [Colour online.]

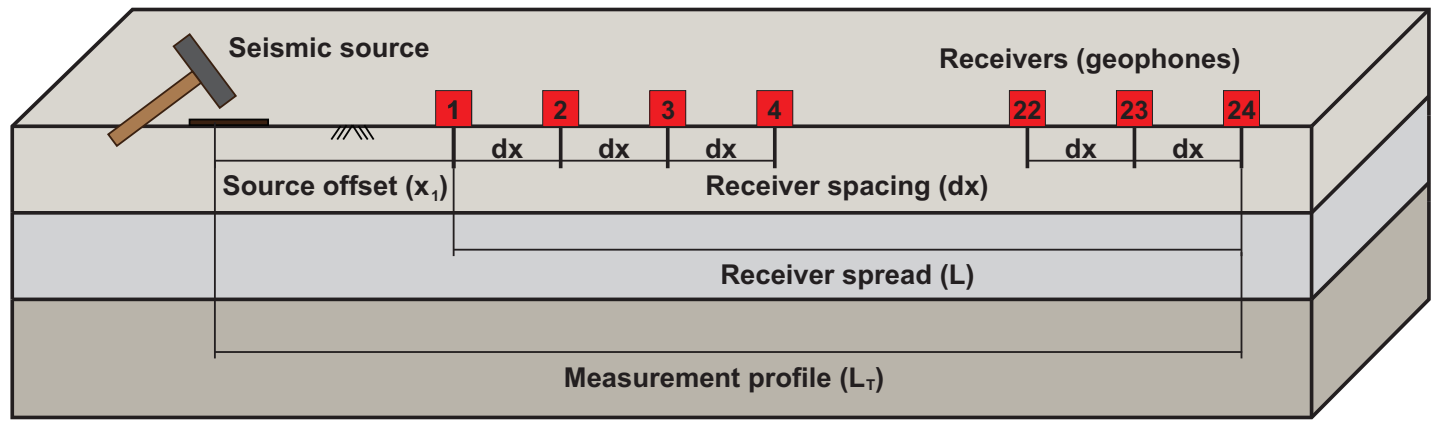

curve up to an acceptable level is taken as the result of the survey (Fig. 1f).

Theoretical dispersion curves are in most cases determined by matrix methods that originate in the work of Thomson (1950) and Haskell (1953), assuming a layered earth model. Various methods have been developed based on the Thomson-Haskell formulation to study surface wave propagation in a layered medium. Many of these were formulated to resolve numerical overflow and loss-ofprecision problems that can occur at high frequencies when the original Thomson-Haskell method is applied (Schwab 1970). Available methods include the propagator-matrix approach described by Knopoff (1964) and Schwab (1970) with later improvements of, e.g., Abo-Zena (1979), Menke (1979), and Buchen and Ben-Hador (1996); the stiffness matrix formulation of Kausel and Roësset (1981); and the reflection-transmission matrix method developed by Kennett (1974) and Kennett and Kerry (1979). In this work, the stiffness matrix method was used for computations of theoretical dispersion curves.
The inversion problem encountered in MASW can be regarded as a nonunique and nonlinear optimization problem where the objective is to minimize the misfit between the theoretical and the experimental dispersion curves (Foti et al. 2015). The inversion can either be performed as a fundamental-mode inversion, i.e., by considering only the fundamental mode of Rayleigh wave propagation, or by including higher modes as well. Fundamental-mode inversion is easier to implement and in general more computationally efficient. However, consideration of higher modes can in some cases be of importance to better constrain the inversion process, especially at sites where the shear wave velocity does not gradually increase with depth (Socco et al. 2010). In this work, the experimental and the theoretical dispersion curves were compared in terms of their fundamental modes.

\section{Dispersion analysis}

A flowchart of the dispersion analysis process is shown in Fig. 3 and a brief description of each step is provided below. A more 
Fig. 3. Overview of the dispersion analysis.

\section{Import data and initialize algorithm}

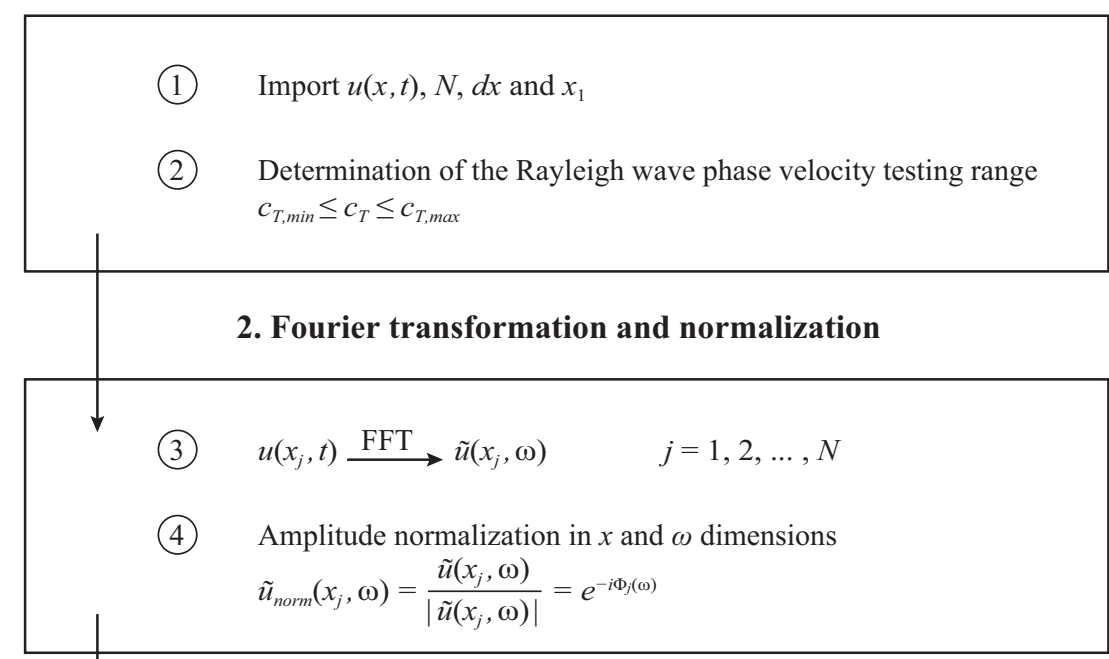

\section{Dispersion imaging}

$\Phi_{T, j}$ : Phase shifts corresponding to a given set of $\omega$ and $c_{T}$

$\Phi_{T, j}=\frac{\omega x_{j}}{c_{T}}=\frac{\omega\left(x_{1}+(j-1) d x\right)}{c_{T}}$

(6) $A_{S}\left(\omega, c_{T}\right)$ : Summed amplitude for a given set of $\omega$ and $c_{T}$

$A_{S}\left(\omega, c_{T}\right)=\frac{1}{N}\left(\mathrm{e}^{-i \Phi_{T, 1}} \tilde{u}_{\text {norm }}\left(x_{1}, \omega\right)+\ldots+\mathrm{e}^{-i \Phi_{T, N}} \tilde{u}_{\text {norm }}\left(x_{N}, \omega\right)\right)$

(7) Steps (5) and (6) repeated for varying $\omega$ and $c_{T}$

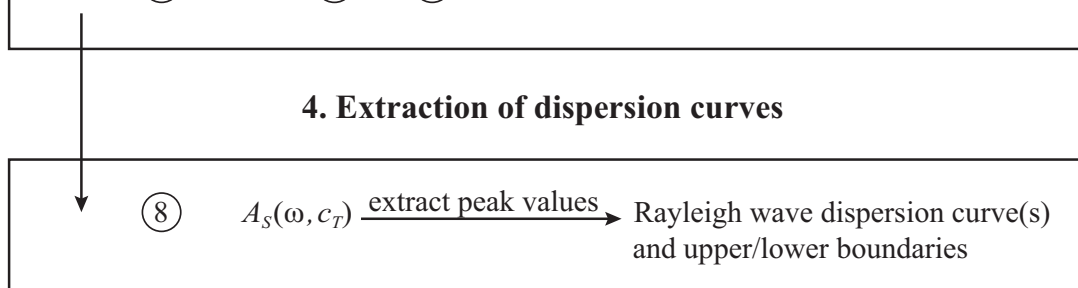

detailed description of the computational procedure is provided by Olafsdottir (2016).

The multichannel surface wave record is denoted by $u\left(x_{j}, t\right)$, where $x_{j}=x_{1}+(j-1) \mathrm{dx}$ is the distance from the impact load point to the $j$ th receiver $(j=1, \ldots, N)$ and $t$ is time. A Fourier transform is applied to each trace of the multichannel record providing its frequency-domain representation $\tilde{u}\left(x_{j}, \omega\right)$ (Park et al. 1998; Park 2011)

$$
\tilde{u}\left(x_{j}, \omega\right)=\operatorname{FFT}\left[u\left(x_{j}, t\right)\right]
$$

where $\omega=2 \pi f$ is angular frequency.

The transformed record can be expressed in terms of amplitude $A_{j}(\omega)$ and phase $\Phi_{j}(\omega)$. The phase term is determined by the characteristic phase velocity of each frequency component $c(\omega)$ and the offset $x_{j}$. The amplitude term preserves information regarding other properties such as the attenuation of the signal and its geometrical spreading (Park et al. 1998; Park 2011)

(3) $\quad \tilde{u}\left(x_{j}, \omega\right)=A_{j}(\omega) \mathrm{e}^{-i \Phi_{j}(\omega)}$ where

(4) $\quad \Phi_{j}(\omega)=\frac{\omega x_{j}}{c(\omega)}=\frac{\omega\left[x_{1}+(j-1) \mathrm{dx}\right]}{c(\omega)}$

and $i^{2}=-1$.

The amplitude of the transformed record is subsequently normalized in both the offset and the frequency dimensions to remove the effects of geometrical spreading and attenuation (Park et al. 1998; Park 2011). Hence, the analysis is focused on the dispersive properties of the signal.

(5) $\quad \tilde{u}_{\text {norm }}\left(x_{j}, \omega\right)=\frac{\tilde{u}\left(x_{j}, \omega\right)}{\left|\tilde{u}\left(x_{j}, \omega\right)\right|}=\mathrm{e}^{-i \Phi_{j}(\omega)}$

The time domain representation of each frequency component of $\tilde{u}_{\text {norm }}\left(x_{j}, \omega\right)$ is an array of normalized sinusoidal curves that have the same phase along the slope determined by their actual phase velocity $c(\omega)$. The phase of the curves varies along slopes corre- 
Fig. 4. Dispersion images obtained by receiver spreads of length $(a) L=11.5 \mathrm{~m}(\mathrm{dx}=0.5 \mathrm{~m}$ and $N=24)$ and $(b) L=23.0 \mathrm{~m}(\mathrm{dx}=1.0 \mathrm{~m}$ and $N=24)$. The midpoint of both receiver spreads was the same. [Colour online.]

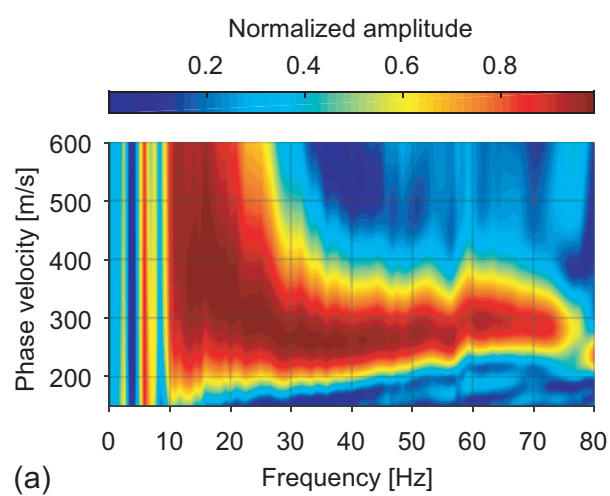

sponding to other phase velocities. If the normalized sinusoidal curves are added up along the slope corresponding to $c(\omega)$, their sum will be another sinusoidal curve with amplitude $N$ through a perfectly constructive superposition. However, if the normalized curves are added up along any other slope, the amplitude of the resulting summed curve will be less than $N$ due to destructive superposition (Ryden et al. 2004; Park 2011). The process of summing amplitudes in the offset domain along slanted paths is generally referred to as slant-stacking (Yilmaz 1987).

For a given testing phase velocity, $c_{\mathrm{T}}$, and a given frequency, $\omega$, the amount of phase shifts required to counterbalance the time delay corresponding to specific offsets $x_{j}$ are determined. The phase shifts are applied to distinct traces of the normalized, transformed record $\tilde{u}_{\text {norm }}\left(x_{j}, \omega\right)$ that are thereafter added to obtain the slant-stacked amplitude $A_{\mathrm{s}}\left(\omega, c_{\mathrm{T}}\right)$ corresponding to each pair of $\omega$ and $c_{\mathrm{T}}$ (Park et al. 1998; Park 2011). The slant-stacked amplitude is generally normalized with respect to $N$ so that the peak value will not depend on the number of receivers

$$
A_{\mathrm{s}}\left(\omega, c_{\mathrm{T}}\right)=\frac{1}{N} \sum_{j=1}^{N} \mathrm{e}^{-i \Phi_{\mathrm{T}}, \tilde{u}_{\mathrm{norm}}}\left(x_{\mathrm{j}}, \omega\right)
$$

where

$$
\Phi_{\mathrm{T}, j}=\frac{\omega x_{j}}{c_{\mathrm{T}}}
$$

The summation operation defined by eqs. (6) and (7) is repeated for all the different frequency components of the transformed record in a scanning manner, changing the testing phase velocity in small increments within a previously specified testing range $\left(c_{\mathrm{T}, \text { min }} \leq c_{\mathrm{T}} \leq c_{\mathrm{T} \text {,max }}\right)$. The dispersion image is thereafter obtained by plotting the slant-stacked amplitude in the frequency-phase velocity domain, in either two or three dimensions (see Figs. $1 c$ and $1 d$ ). The high-amplitude bands visualize the dispersion properties of all types of waves contained in the recorded data and are used to construct the fundamental-mode (and higher-mode) dispersion curve(s) for the site (Park et al. 1998; Park 2011). Upper and lower boundaries for the modal dispersion curves $\left(\left(p_{A} / 100\right) A_{\mathrm{s}, \max } \leq\right.$ $A_{\mathrm{s}} \leq A_{\mathrm{s}, \mathrm{max}}$ ) can be obtained by identifying the testing phase velocity values that provide $p_{A} \%$ of the corresponding spectral peak value $\left(A_{\mathrm{s}, \max }\right)$ at each frequency.

The experimental fundamental-mode dispersion curve is denoted by $\left(c_{\mathrm{e}, q}, \lambda_{\mathrm{e}, q}\right)(q=1, \ldots, Q)$ where $Q$ is the number of data points, $c_{\mathrm{e}, q}$ is the Rayleigh wave phase velocity of the $q$ th data point, and $\lambda_{\mathrm{e}, q}$ is the corresponding wavelength. For application of the software MASWaves, the fundamental-mode dispersion curve is of main interest and also referred to as the dispersion curve in the subsequent discussion.

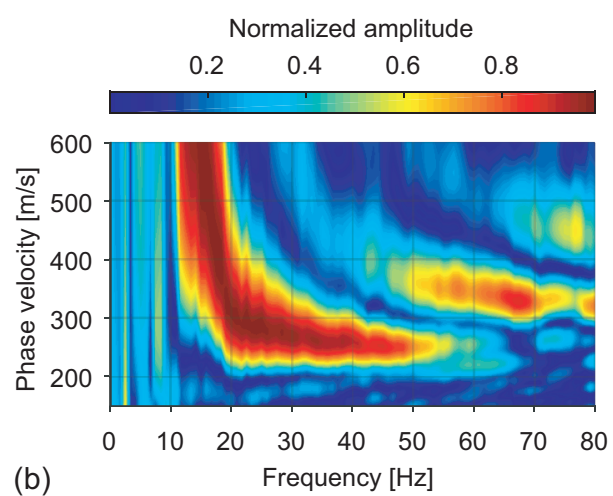

Challenges associated with the dispersion analysis and effects of the measurement profile configuration

Determination of the experimental Rayleigh wave dispersion curve is a critical stage in the application of MASW. An inaccurate or erroneous experimental dispersion curve can cause substantial errors in the inverted shear wave velocity profile (Gao et al. 2016; Park et al. 1999; Zhang and Chan 2003).

Ideally, the dispersion analysis should provide identification and extraction of the dispersion curve for each mode. However, in reality, surface wave registrations are incomplete to some extent, imposing various challenges when dispersion curves are identified based on a dispersion image. The fundamental mode of Rayleigh wave propagation typically prevails at sites where the stiffness (shear wave velocity) increases gradually with increasing depth (Foti et al. 2015; Gao et al. 2016; Gucunski and Woods 1991; Tokimatsu et al. 1992). However, at sites characterized by a more irregularly varying stiffness profile, e.g., the presence of a stiff surface layer, a stiff layer sandwiched between two softer layers or a sudden increase in stiffness with depth, higher modes can play a significant role in certain frequency ranges. In such cases, misidentification of mode numbers or superposition of dispersion data from two (or more) modes can occur (Foti et al. 2015; Gao et al. 2016; Zhang and Chan 2003). Mode misidentification can, for example, involve a higher mode being incorrectly identified as the fundamental mode, whereas mode superposition results in an apparent dispersion curve that does not correspond to any of the real modes. Such overestimation of the fundamental-mode phase velocity will, in the inversion analysis, lead to both overestimation of the shear wave velocity and erroneous depth.

The length of the receiver spread $(L)$ affects the spectral resolution of the dispersion image, i.e., the width of the high-amplitude band, and hence, the ability to separate different modes of Rayleigh wave propagation as well as the accuracy of the identified spectral maximum at each frequency (Foti et al. 2015). This is illustrated in Fig. 4. The dispersion image in Fig. $4 a$ was obtained based on a multichannel record acquired by a receiver spread of length $11.5 \mathrm{~m}$, whereas the data used for computation of Fig. $4 b$ were obtained at the same test site using a $23.0 \mathrm{~m}$ receiver spread. The receiver spread length of $11.5 \mathrm{~m}$ was not sufficient to separate the fundamental and higher modes. However, the longer receiver spread provided improved spectral resolution and allowed identification of a higher mode at frequencies above $40-50 \mathrm{~Hz}$. The use of an even longer receiver spread was not possible due to the nature of the site.

Based on the previous discussion, a longer receiver spread is, in general, preferable to improve the resolution of the dispersion image. However, an increased receiver spread length risks significant lateral variations along the geophone array (thus violating the one-dimensional soil model assumption made in the inversion analysis), attenuation of higher frequency surface wave com- 
Fig. 5. Test site 1: dispersion images obtained by (a) MASWaves and (b) Geopsy. [Colour online.]
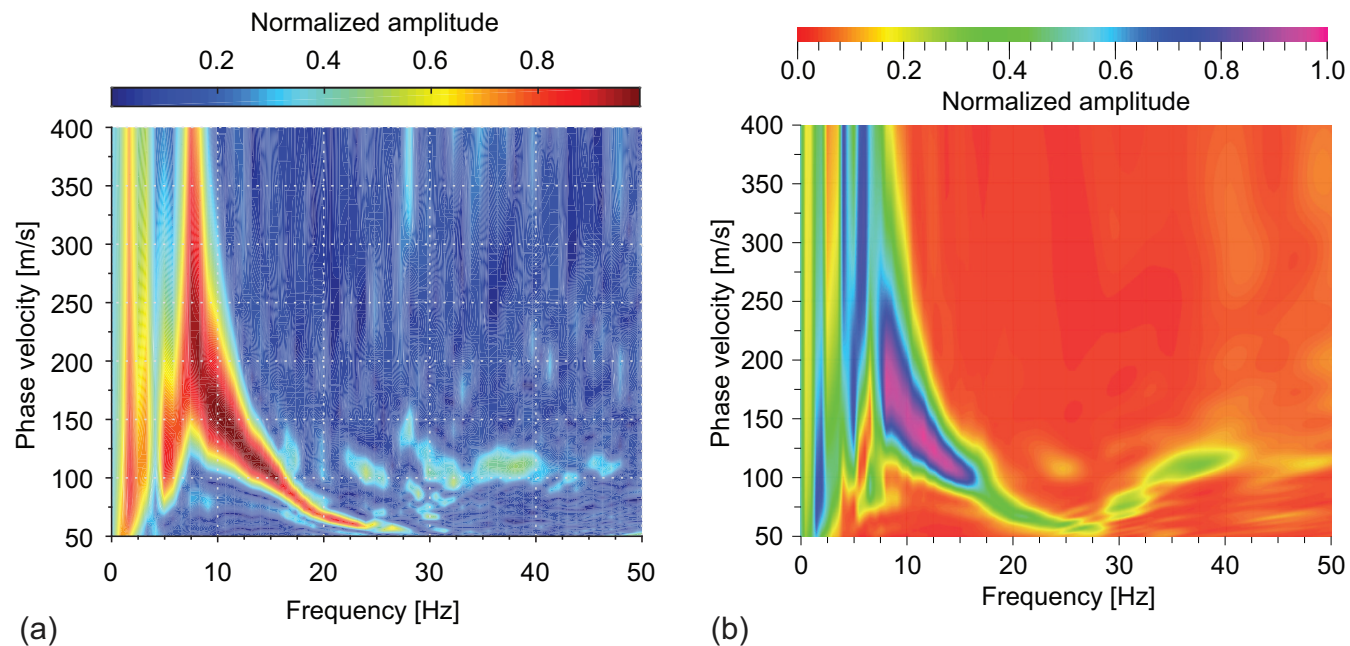

(b)

Fig. 6. Test site 2: dispersion images obtained by (a) MASWaves and (b) Geopsy. [Colour online.]

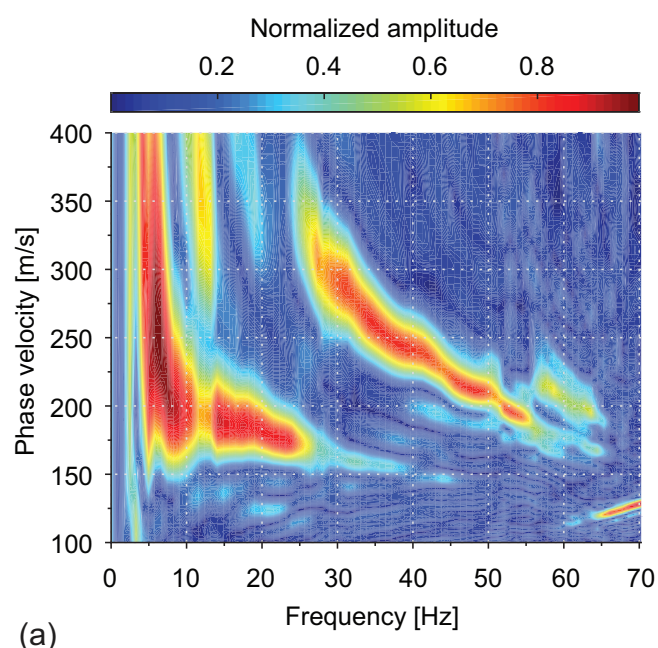

(a)

ponents (which reduces the minimum resolvable investigation depth of the survey), and spatial aliasing if a fixed number of receivers is used (Foti et al. 2015).

The analysis of the multichannel surface wave records is based on the assumption that the wave front of the Rayleigh wave is plane. Hence, propagation of nonplanar surface waves and interference of body waves near the impact load point, referred to as near-field effects, can bias the experimental dispersion curve estimate (Ivanov et al. 2008; Park and Carnevale 2010; Yoon and Rix 2009). In general, the length of the source offset $\left(x_{1}\right)$ has to be sufficient to assure plane wave propagation of surface wave components. The minimum source offset required to avoid near-field effects depends on the longest wavelength that is analysed. A very short source offset can result in an irregular and unreliable highamplitude trend in the dispersion image at lower frequencies, usually displaying lower phase velocities than images free of nearfield effects. An overly long source offset, however, risks excessive attenuation of fundamental-mode components at higher frequencies. A simple, widely accepted rule-of-thumb indicates that the investigation depth of the survey is around the same as the receiver spread length $(L)$ and that the minimum source offset is in the range of $0.25 \mathrm{~L}-\mathrm{L}$ (Ivanov et al. 2008). However, it should be noted that such empirical rules-of-thumb might not be applicable at specific sites.

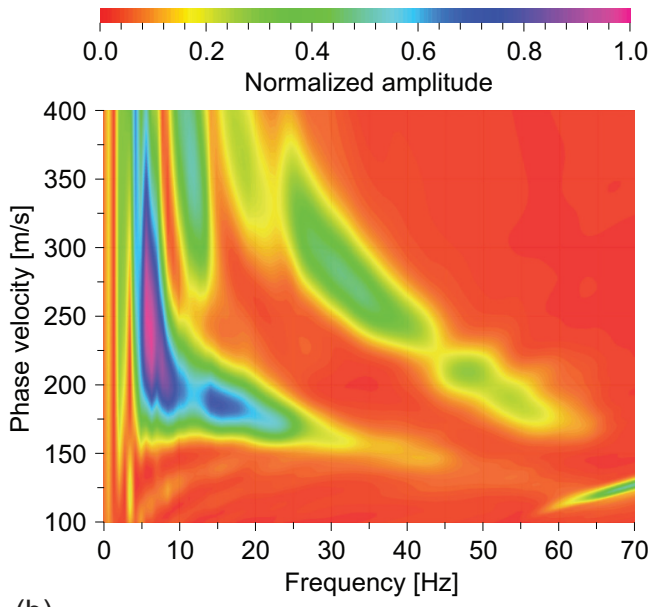

(b)

\section{Validation of the dispersion analysis procedure}

The dispersion analysis procedure implemented in MASWaves has been verified by comparison with the Linear F-K for active experiments toolbox of the Geopsy software package (geopsy.org). The comparison is provided in the form of dispersion images and extracted fundamental- and higher-mode dispersion curves. Multichannel surface wave records acquired at two test sites in north Iceland were used for comparison purposes. At test site 1, the fundamental mode dominated the surface wave signal (Fig. 5). At test site 2 , however, a higher mode was dominant at frequencies higher than $25-30 \mathrm{~Hz}$ (Fig. 6). At both test sites, the two computational procedures provided fundamental-mode Rayleigh wave dispersion curve estimates within the approximately same frequency ranges, as well as higher-mode dispersion curve estimates within comparable frequency ranges at test site 2 . The extracted fundamental-and higher-mode dispersion curves agreed very well in both cases (Fig. 7).

\section{Inversion analysis}

Figure 8 illustrates the stratified earth model used in the inversion analysis. For computation of a theoretical dispersion curve corresponding to the assumed layer structure, the problem is approximated as a plane strain problem in the $x-z$ plane (Haskell 
Fig. 7. (a) Test site 1: comparison of fundamental-mode dispersion curves extracted from the spectra in Figs. $5 a$ and $5 b$. (b) Test site 2: comparison of fundamental- and higher-mode dispersion curves extracted from the spectra in Figs. $6 a$ and 6b. [Colour online.]

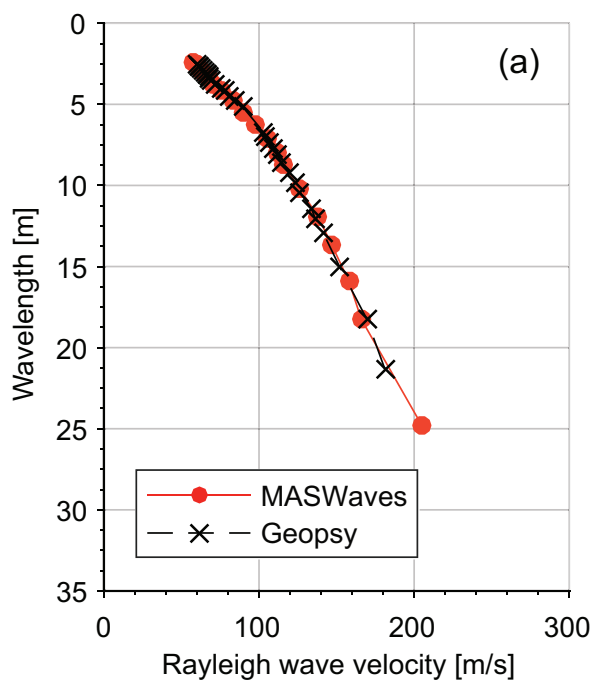

Fig. 8. A layered soil model for the inversion analysis. [Colour online.]

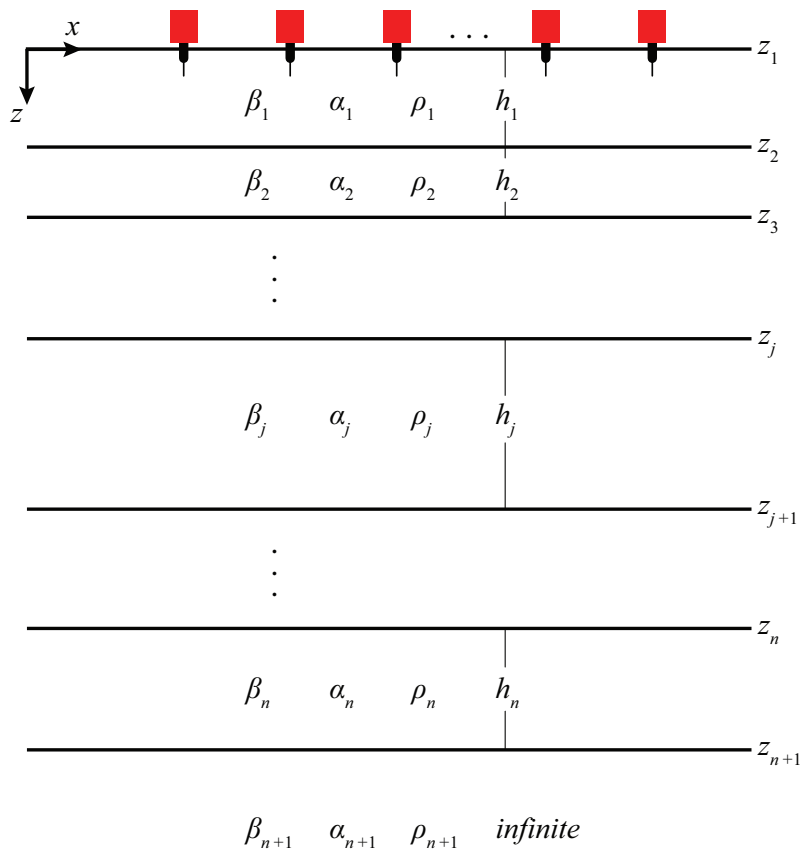

1953; Kausel and Roësset 1981). The $x$-axis is parallel to the layers, with a positive $x$ in the direction of surface wave propagation, and the positive $z$-axis is directed downwards. Each layer is assumed to be flat and have homogeneous and isotropic properties. The top of the first layer corresponds to the surface of the earth. The number of finite thickness layers is denoted by $n$. The last layer, referred to as layer $n+1$, is assumed to be a half-space. The parameters required to define the properties of each layer are layer thickness $(h)$, shear wave velocity $(\beta)$, Poisson's ratio $(\nu)$ or compressional wave velocity $(\alpha)$ and mass density $(\rho)$.

An overview of the inversion analysis procedure is provided in Fig. 9. The first step is to obtain an initial estimate of the required model parameters. For a plane-layered earth model, the shear wave velocity has a dominant effect on the fundamental-mode dispersion curve at frequencies $f>5 \mathrm{~Hz}$, followed by layer thicknesses (Xia et al. 1999). As the effect of change in Poisson's ratio (or

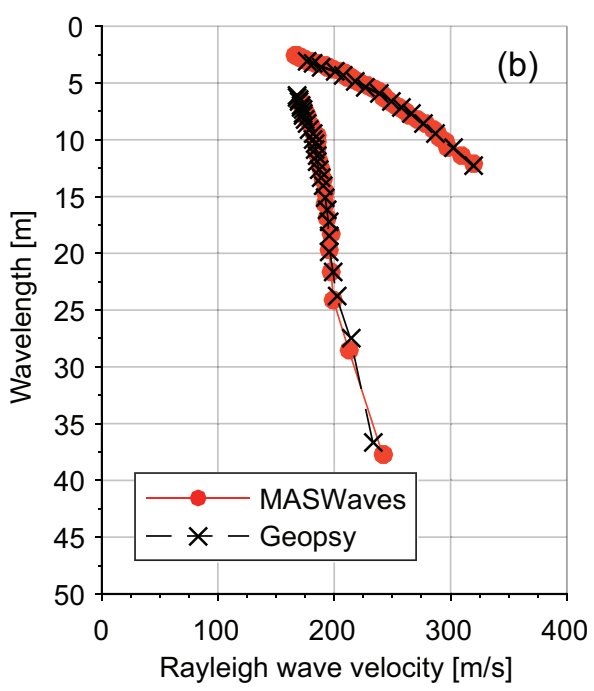

compressional wave velocity) and mass density are less significant, these parameters are assumed known and assigned fixed values to simplify the inversion process.

The layer thicknesses and the initial shear wave velocity of each layer can be estimated based on the experimental dispersion curve $\left(c_{\mathrm{e}, q}, \lambda_{\mathrm{e}, q}\right)(q=1, \ldots, Q)$ utilizing a methodology described by Park et al. (1999) where the shear wave velocity, $\beta$, at depth $z$ is estimated as 1.09 times the experimental Rayleigh wave phase velocity, $c$, at the frequency where the wavelength, $\lambda$, fulfils

(8) $\quad z=a \lambda$

The parameter $a$ is a coefficient that does not change considerably with frequency (Park et al. 1999) and can be chosen close to 0.5 (see eq. (1)). The multiplication factor 1.09 originates from the ratio between the shear and Rayleigh wave propagation velocities in a homogeneous medium (Kramer 1996). Alternatively, the initial values of the layer thicknesses and the shear wave velocities can be assigned manually.

The Poisson's ratio (or the compressional wave velocity) and the mass density of each layer are either estimated based on independent soil investigations or experience of similar soil types from other sites. For estimation of these parameters, it is important to pay special attention to the presence and the expected position of the groundwater table. The velocity of compressional waves propagating through groundwater is close to $1500 \mathrm{~m} / \mathrm{s}$, depending slightly on water temperature and salinity (Kramer 1996). Their propagation velocity through soft, saturated soil can reach these high velocities. Hence, in such cases the compressional wave velocity is not indicative of the stiffness of the saturated soil and the soil's apparent Poisson's ratio will be close to 0.5 (Foti et al. 2015; Gazetas 1991). The saturated density should be used for the soil layers that are below the expected groundwater table. The stiffness of the soft soil can be significantly overestimated if the presence of the groundwater table is ignored (Kramer 1996).

Theoretical fundamental-mode dispersion curves are computed by the stiffness matrix method of Kausel and Roësset (1981) in an iterative way. In each iteration, the theoretical fundamentalmode dispersion curve $\left(c_{\mathrm{t}, q}, \lambda_{\mathrm{t}, q}\right)(q=1, \ldots, Q)$ is computed at the same wavelengths as are included in the experimental dispersion curve $\left(c_{\mathrm{e}, q}, \lambda_{\mathrm{e}, q}\right)(q=1, \ldots, Q)$, i.e.,

$$
\lambda_{\mathrm{t}, q}=\lambda_{\mathrm{e}, q} \quad q=1, \ldots, Q
$$


Fig. 9. Overview of the inversion analysis.

\section{Initial estimate of model parameters}

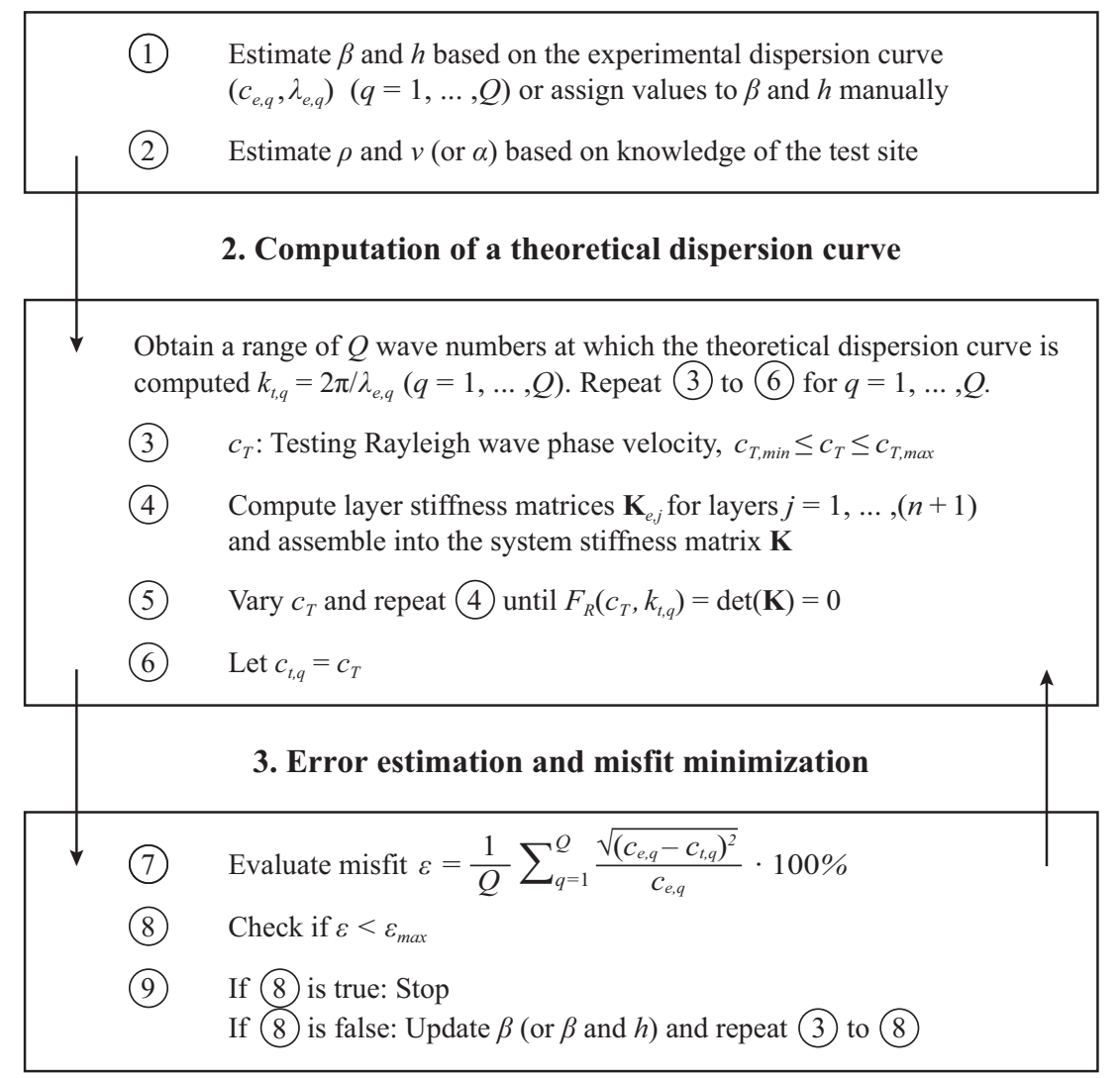

The corresponding wave numbers $k_{\mathrm{t}, q}$ are

$$
k_{\mathrm{t}, q}=\frac{2 \pi}{\lambda_{\mathrm{t}, q}} \quad q=1, \ldots, Q
$$

An element stiffness matrix $\mathbf{K}_{\mathrm{e}, j}$ is obtained for each layer, including the half-space, for a given value of $k_{\mathrm{t}, q}$ and an assumed testing phase velocity $c_{\mathrm{T}}$. The element stiffness matrix of a given layer relates the stresses at the upper and lower interfaces of the layer to the corresponding displacements (Kausel and Roësset 1981)

$$
\boldsymbol{p}_{\mathrm{e}, j}=\mathbf{K}_{\mathrm{e}, j} \boldsymbol{u}_{\mathrm{e}, j} \quad j=1, \ldots,(n+1)
$$

where $\boldsymbol{p}_{\mathrm{e}, j}$ is the element external load vector of the $j$ th layer and $\boldsymbol{u}_{\mathrm{e}, j}$ is the element displacement vector of the jth layer. Equation (11) is referred to as the element matrix equation for the $j$ th layer. The components of the element stiffness matrix $\mathbf{K}_{\mathrm{e}, j}$ are provided in Appendix A.

The element matrix equations (eq. (11)) are subsequently assembled at the common layer interfaces (see Appendix A) to form the system equation

$$
\boldsymbol{p}=\mathbf{K u}
$$

where the matrix $\mathbf{K}$ is referred to as the system stiffness matrix and the vectors $\boldsymbol{p}$ and $\boldsymbol{u}$ are the system external load vector and the system displacement vector, respectively. The natural modes of Rayleigh wave propagation are obtained by considering a system with no external loading, i.e., where
(13) $\quad \mathbf{K u}=0$

For nontrivial solutions of eq. (13), the determinant of the system stiffness matrix $\mathbf{K}$ must vanish. Hence, wave numbers that represent the modal solutions at various frequencies are obtained as the solutions of

$$
F_{\mathrm{R}}(c, k)=\operatorname{det}(\mathbf{K})=0
$$

For a given value of $k_{\mathrm{t}, q}$, the solution of the dispersion equation (eq. (14)) is determined by varying the testing phase velocity, $c_{\mathrm{T}}$, in small increments $\left(\Delta c_{\mathrm{T}}\right)$, starting from an underestimated initial value, and recomputing the system stiffness matrix until its determinant has a sign change. The testing phase velocity increment $\left(\Delta c_{\mathrm{T}}\right)$ is an input parameter of MASWaves Inversion. Based on testing of the program, its recommended value is in the range of $\Delta c_{\mathrm{T}} \in[0.1,0.5] \mathrm{m} / \mathrm{s}$, with $\Delta c_{\mathrm{T}}=0.1 \mathrm{~m} / \mathrm{s}$ recommended for soil layer models characterized by an irregularly varying shear wave velocity (stiffness) profile where a higher mode can be expected to play a significant role. For computations based on earth models where the shear wave velocity increases gradually with depth, a larger value of $\Delta c_{\mathrm{T}}$ (e.g., $\Delta c_{\mathrm{T}}=1 \mathrm{~m} / \mathrm{s}$ ) is, however, in many cases sufficient. As a consequence of choosing a too large value of $\Delta c_{\mathrm{T}}$, the algorithm may fail to correctly separate the fundamental- and highermode dispersion curves, especially at osculation points or "mode kissing" points where the fundamental- and first higher-mode dispersion curves are very close to each other.

As the value of $c_{\mathrm{T}}$ that provides the fundamental-mode solution of eq. (14) has been obtained with sufficient accuracy, the value of $c_{\mathrm{t}, q}$ is taken as 
Table 1. Test profile, case A (after Xia et al. 2007).

\begin{tabular}{lllll}
\hline $\begin{array}{l}\text { Layer } \\
\text { number }\end{array}$ & $\begin{array}{l}\text { Shear wave } \\
\text { velocity }(\mathrm{m} / \mathrm{s})\end{array}$ & $\begin{array}{l}\text { Compressional wave } \\
\text { velocity }(\mathrm{m} / \mathrm{s})\end{array}$ & $\begin{array}{l}\text { Mass density } \\
\left(\mathrm{kg} / \mathrm{m}^{3}\right)\end{array}$ & $\begin{array}{l}\text { Layer } \\
\text { thickness }(\mathrm{m})\end{array}$ \\
\hline 1 & 200 & 800 & 2000 & 10.0 \\
2 (half-space) & 400 & 1200 & 2000 & Infinite \\
\hline
\end{tabular}

Table 2. Test profile, case B (after Xia et al. 1999).

\begin{tabular}{lllll}
\hline $\begin{array}{l}\text { Layer } \\
\text { number }\end{array}$ & $\begin{array}{l}\text { Shear wave } \\
\text { velocity }(\mathrm{m} / \mathrm{s})\end{array}$ & $\begin{array}{l}\text { Compressional wave } \\
\text { velocity }(\mathrm{m} / \mathrm{s})\end{array}$ & $\begin{array}{l}\text { Mass density } \\
\left(\mathrm{kg} / \mathrm{m}^{3}\right)\end{array}$ & $\begin{array}{l}\text { Layer } \\
\text { thickness }(\mathrm{m})\end{array}$ \\
\hline 1 & 194 & 650 & 1820 & 2.0 \\
2 & 270 & 750 & 1860 & 2.3 \\
3 & 367 & 1400 & 1910 & 2.5 \\
4 & 485 & 1800 & 1960 & 2.8 \\
5 & 603 & 2150 & 2020 & 3.2 \\
6 (half-space) & 740 & 2800 & 2090 & Infinite \\
\hline
\end{tabular}

Fig. 10. Comparison of theoretical dispersion curves obtained by MASWaves and the software WinSASW: (a) case A and (b) case B. [Colour online.]
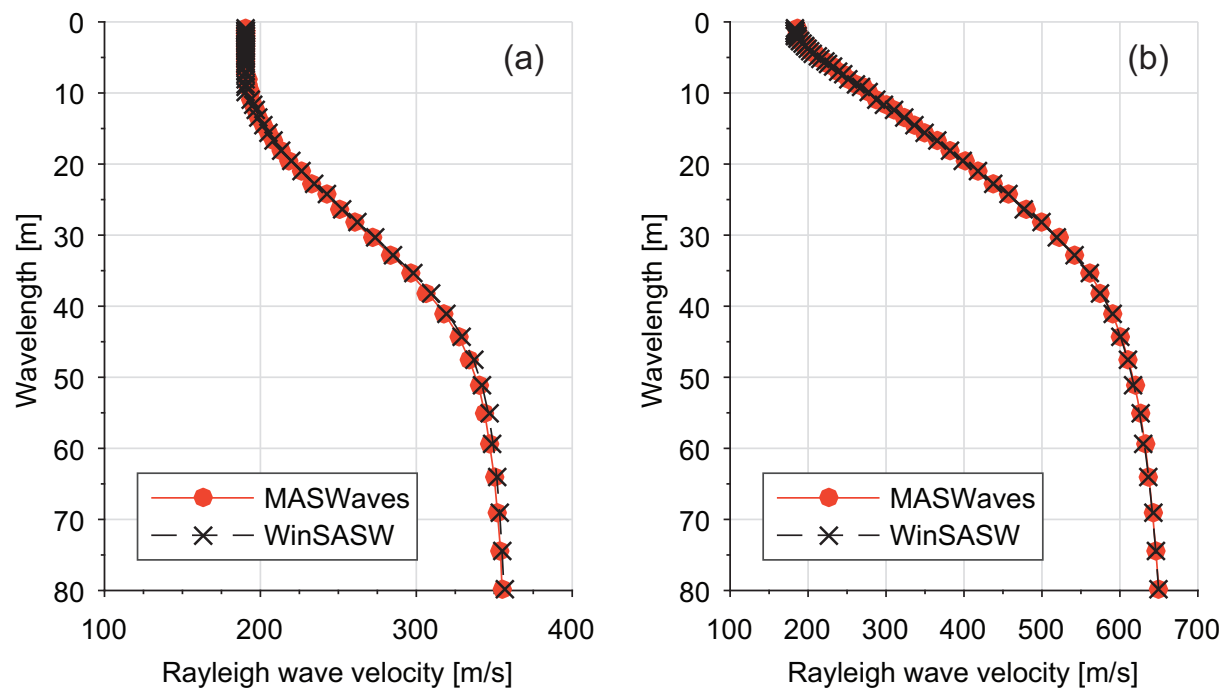

Table 3. Test profiles, cases 1, 2, and 3 (after Tokimatsu et al. 1992 and Tokimatsu 1997).

\begin{tabular}{lcccclll}
\hline & \multicolumn{2}{l}{ Shear wave velocity $(\mathrm{m} / \mathrm{s})$} & & \\
\cline { 2 - 5 } $\begin{array}{l}\text { Layer } \\
\text { number }\end{array}$ & Case 1 & Case 2 & Case 3 & $\begin{array}{l}\text { Compressional wave } \\
\text { velocity }(\mathrm{m} / \mathrm{s})\end{array}$ & $\begin{array}{l}\text { Mass density } \\
\left(\mathrm{kg} / \mathrm{m}^{3}\right)\end{array}$ & $\begin{array}{l}\text { Layer } \\
\text { thickness }(\mathrm{m})\end{array}$ \\
\hline 1 & 80 & 180 & 80 & 360 & 1800 & 2.0 \\
2 & 120 & 120 & 180 & 1000 & 1800 & 4.0 \\
3 & 180 & 180 & 120 & 1400 & 1800 & 8.0 \\
4 (half-space) & 360 & 360 & 360 & 1400 & 1800 & Infinite \\
\hline
\end{tabular}

(15)

$$
c_{\mathrm{t}, q}=c_{\mathrm{T}}
$$

By repeating the computations for different wave numbers $k_{\mathrm{t}, \mathrm{q}}$ (different wavelengths $\lambda_{t, q}$ ), the theoretical fundamental-mode dispersion curve is constructed.

The misfit $\epsilon$ between the theoretical dispersion curve and the observed experimental curve is subsequently evaluated as

$$
\epsilon=\frac{1}{Q} \sum_{q=1}^{Q} \frac{\sqrt{\left(c_{\mathrm{e}, q}-c_{\mathrm{t}, q}\right)^{2}}}{c_{\mathrm{e}, q}} \times 100 \%
$$

If a given estimate of the model parameters does not provide a theoretical dispersion curve that is sufficiently close to the exper- imental curve, the shear wave velocity profile and (or) the layer structure needs to be updated manually by the user. The iteration procedure is terminated when $\epsilon$ has reached an acceptably small value, i.e., when $\epsilon<\epsilon_{\max }$, where $\epsilon_{\max }$ is the maximum allowed misfit. A maximum misfit of $2.0 \%-5.0 \%$ is commonly used by the authors. In the field tests presented later in the paper, the maximum misfit was specified as $2.0 \%$. It should, however, be noted that the suggested range for the maximum misfit, as computed by eq. (16), is solely based on the authors' experience and may not be applicable in all cases.

The results of the inversion analysis are provided in the form of experimental and theoretical dispersion curves, estimated shear wave velocity as a function of depth, and the time-average shear wave velocity, $V_{\mathrm{S}, d}$, computed for different depths $d$ (CEN 2004) 
Fig. 11. Comparison of theoretical fundamental- and first higher-mode dispersion curves obtained by MASWaves and presented by Tokimatsu et al. (1992) and Tokimatsu (1997): (a) case 1, (b) case 2, and (c) case 3. [Colour online.]

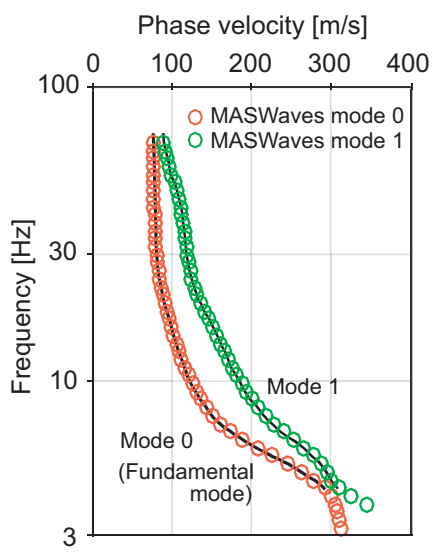

(a)

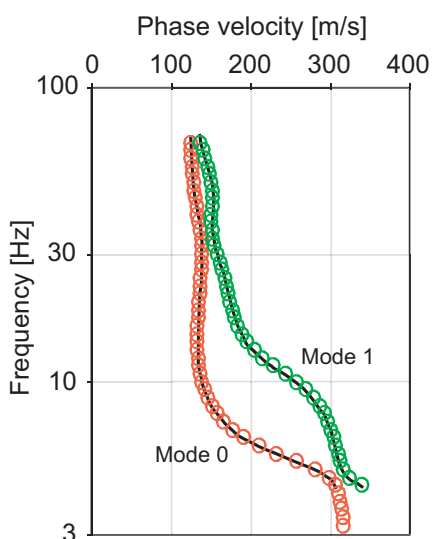

(b)

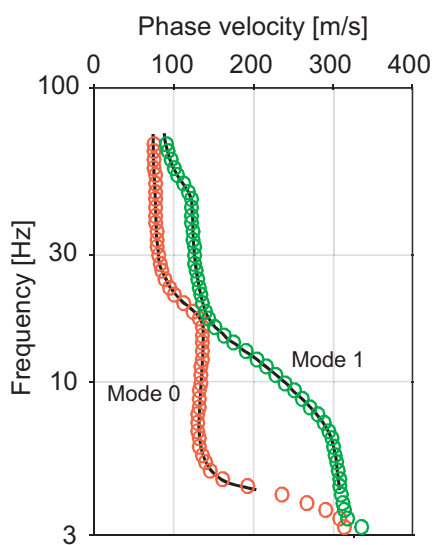

(c)

Fig. 12. Location of MASW test sites in south Iceland (map is based on data from the National Land Survey of Iceland). [Colour online.]

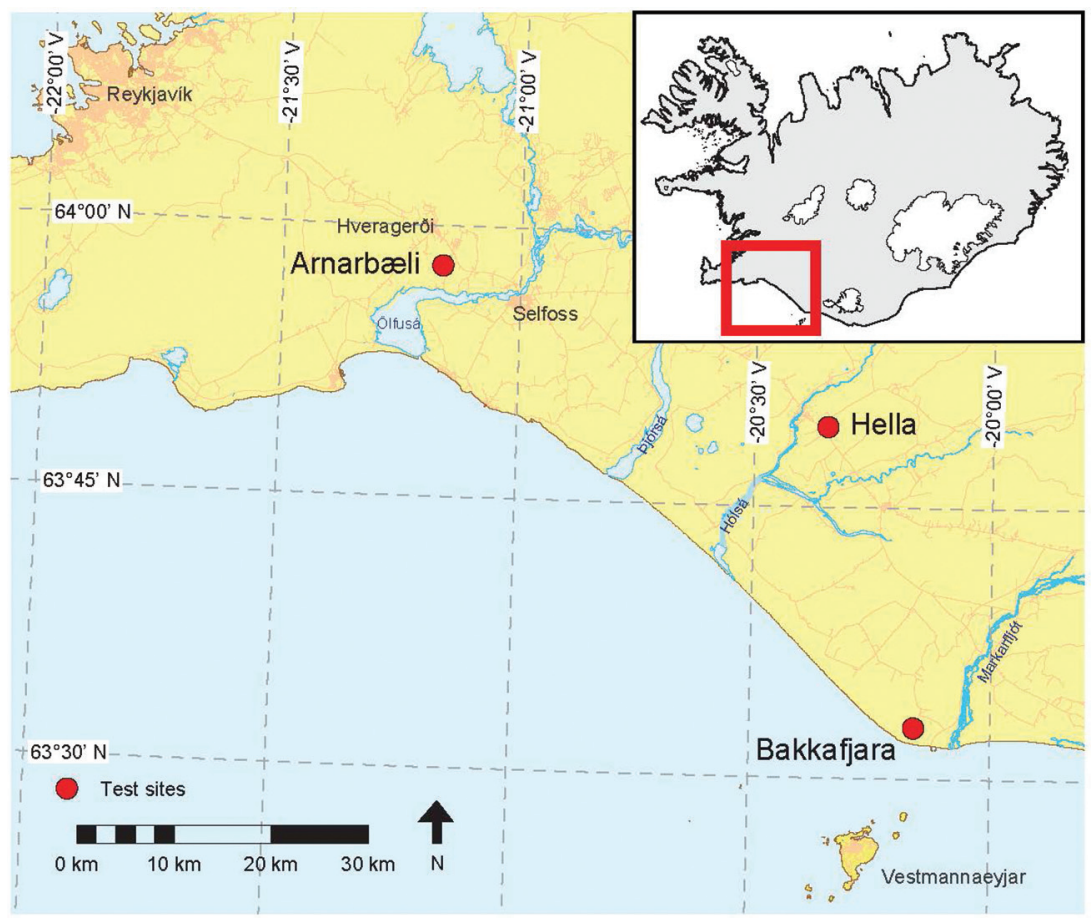

$$
V_{\mathrm{S}, d}=\frac{d}{\sum_{j=1}^{M} \frac{h_{j}}{\beta_{j}}}
$$

where $\beta_{j}$ and $h_{j}$ denote the shear wave velocity and the thickness of the $j$ th layer, respectively, for a total of $M$ layers. If the estimated shear wave velocity profile goes down to a depth less than $d$, the profile is extrapolated using the half-space velocity (Fig. 8) down to depth $d$.

\section{Challenges associated with the inversion analysis}

For this paper, a manual (trial-and-error) inversion was used, i.e., the parameters of the initially estimated soil layer model were gradually adjusted to minimize the misfit between the experimental and theoretical dispersion curves. On one hand, a manual search is to a certain extent operator-dependent and requires a certain experience to achieve an acceptable fit within a reason- able amount of time. On the other hand, a manual search can represent the only viable approach if automatic local or global search algorithms fail to converge (Foti et al. 2015).

The goal of the inversion analysis is to obtain a shear wave velocity profile that realistically represents the characteristics of the test site. The inverse problem faced during this stage of the analysis is by nature ill-posed, nonlinear, mix-determined, and nonunique, i.e., multiple significantly different shear wave velocity profiles can provide theoretical dispersion curves that correspond similarly well (provide comparable misfits) to the measured data (Cox and Teague 2016; Foti et al. 2015). Hence, when available, a priori information about the test site should be used to constrain the inversion process to some extent and aid the selection of realistic shear wave velocity profiles. In cases where such data are not available, the operator must decide blindly the number of layers, credible ranges for the required inversion parameters (layer thicknesses and shear wave velocity values for each layer), 
Table 4. Overview of site characteristics, test configuration, and analysis results at the Arnarbæli, Bakkafjara, and Hella test sites in south Iceland.

\begin{tabular}{|c|c|c|c|}
\hline & Arnarbæli & Bakkafjara & Hella \\
\hline \multicolumn{4}{|l|}{ Site characteristics } \\
\hline Soil type & Holocene glaciofluvial sand & Modern littoral sand & $\begin{array}{l}\text { Late-glacial (slightly) cemented } \\
\text { aeolian silty sand }\end{array}$ \\
\hline USCS classification & SW-SM* & $\mathrm{SW}^{\dagger}$ & - \\
\hline Location of groundwater table & At surface ${ }^{\ddagger}$ & At $4 \mathrm{~m} \mathrm{depth}^{\S}$ & - \\
\hline Mass density, $\rho\left(\mathrm{kg} / \mathrm{m}^{3}\right)$ & - & 1850 & 2200 \\
\hline Saturated mass density, $\rho_{\text {sat }}\left(\mathrm{kg} / \mathrm{m}^{3}\right)$ & $1850^{*}$ & 2000 & - \\
\hline Poisson's ratio, $\nu$ & - & 0.35 & 0.35 \\
\hline \multicolumn{4}{|l|}{ Field measurements } \\
\hline Month/year of MASW field test & 09/2013, 08/2014, 07/2015 & $08 / 2014$ & 07/2015 \\
\hline Number of geophones, $\mathrm{N}$ & 24 & 24 & 24 \\
\hline Receiver spacing, dx (m) & 1.0 & 2.0 & 1.0 \\
\hline Source offset, $x_{1}(\mathrm{~m})$ & 10.0 & 15.0 & 10.0 \\
\hline Sampling rate, $f_{\mathrm{s}}(\mathrm{Hz})$ & 1000 & 1000 & 1000 \\
\hline Recording time, $\mathrm{T}(\mathrm{s})$ & 1.2 & 1.2 & 1.2 \\
\hline \multicolumn{4}{|l|}{ Dispersion analysis } \\
\hline $\begin{array}{l}\text { Frequency range for fundamental- } \\
\text { mode dispersion curve }(\mathrm{Hz})\end{array}$ & $7.5-22.5$ & $5.8-33.3$ & $15.7-60.3$ \\
\hline \multicolumn{4}{|l|}{ Inversion analysis } \\
\hline $\begin{array}{l}\text { Misfit between theoretical and } \\
\text { experimental curves, } \epsilon(\%)\end{array}$ & 1.8 & 1.8 & 1.5 \\
\hline Maximum misfit, $\epsilon_{\max }(\%)$ & 2.0 & 2.0 & 2.0 \\
\hline $\begin{array}{l}\text { Time-average shear wave velocity } \\
\text { of the uppermost } 30 \mathrm{~m}, V_{\mathrm{S}, 30}(\mathrm{~m} / \mathrm{s})\end{array}$ & 204 & 218 & 558 \\
\hline Soil classification (EC8)\| & $\mathrm{C}$ & $\mathrm{C}$ & B \\
\hline $\begin{array}{l}\text { Note: USCS, Unified Soil Classification S } \\
{ }^{*} \text { Green et al. (2012). } \\
{ }^{\dagger} \text { Bessason and Erlingsson (2011). } \\
\text { ‡Olafsdottir et al. (2015). } \\
\text { §Olafsdottir et al. (2016). } \\
\text { "CEN (2004). }\end{array}$ & ystem. & & \\
\hline
\end{tabular}

and the location of the groundwater table. The layering parameterization plays a critical role in the inversion analysis and has been shown to critically affect its outcome (Di Giulio et al. 2012; Cox and Teague 2016). An inappropriate parameterization can result in either an overly simplistic or complicated shear wave velocity profile that, despite a low misfit value, does not correctly represent the characteristics of the test site. As a countermeasure it is recommended to try multiple parameterizations to increase the likelihood of obtaining a realistic shear wave velocity profile and to evaluate the uncertainty associated with those profiles (Cox and Teague 2016).

\section{Validation of the theoretical dispersion curve computations}

The ability of MASWaves Inversion to compute theoretical dispersion curves has been verified by comparison with the software WinSASW (version 1.2; UTAustin 1992) and results presented by Tokimatsu et al. (1992) and Tokimatsu (1997).

Two sets of earth model parameters, both used previously for generation of synthetic surface wave data in references (see Tables 1 and 2), are used here as examples of comparison of theoretical fundamental-mode dispersion curves obtained by MASWaves Inversion and WinSASW (version 1.2). Both soil layer models (i.e., cases A and B) are normally dispersive without strong velocity contrasts and thus represent sites where the fundamental mode of Rayleigh wave propagation is expected to prevail.

The theoretical fundamental-mode dispersion curves were computed for the same wavelengths in the range of $0-80 \mathrm{~m}$. In WinSASW, the two-dimensional analysis option was used for computation of the curves. For application of MASWaves, the testing phase velocity increment $\left(\Delta c_{\mathrm{T}}\right)$ was specified as $1 \mathrm{~m} / \mathrm{s}$. In both cases, the agreement between the two computational methods was good (Fig. 10).
For further confirmation of the ability of MASWaves Inversion to separate fundamental- and higher-mode dispersion curves, as well as to comply with more complex layering, the program was tested on three additional soil layer modes, all used previously by Tokimatsu et al. (1992) and Tokimatsu (1997). The three four-layer models, referred to as cases 1,2 , and 3, are listed in Table 3 . In case 1 , the shear wave velocity (stiffness) increases with increasing depth. The stiffness of the soil layers varies more irregularly in cases 2 and 3, i.e., a stiff surface layer is present in case 2 and a stiff layer is located between two softer layers in case 3 . Hence, in cases 2 and 3 , the higher modes play a more significant role (Tokimatsu et al. 1992; Tokimatsu 1997).

Using MASWaves, the theoretical fundamental- and first higher-mode dispersion curves were computed for frequencies in the range of 3-70 Hz using a testing phase velocity increment $\left(\Delta c_{\mathrm{T}}\right)$ of $0.1 \mathrm{~m} / \mathrm{s}$. The comparison of the fundamental- and first highermode dispersion curves obtained by MASWaves and those presented by Tokimatsu et al. (1992) and Tokimatsu (1997) is illustrated in Fig. 11. In Fig. 11, the curves obtained by MASWaves are indicated by circles, whereas the dispersion curves of Tokimatsu et al. (1992) and Tokimatsu (1997) are shown with black lines. In all three cases, the agreement between the fundamentaland first higher-mode dispersion curves obtained by MASWaves and Tokimatsu et al. (1992) and Tokimatsu (1997) was good.

\section{Field tests}

MASW measurements were conducted at three locations in south Iceland - Arnarbæli, Bakkafjara, and Hella - between 2013 and 2015 (see Fig. 12 and Table 4). At the three test sites, surface wave records were collected using a linear array of 24 vertical geophones (GS-11D from Geospace Technologies, Houston, Texas) with a natural frequency of $4.5 \mathrm{~Hz}$ and a critical damp- 
Fig. 13. 24-channel surface wave record acquired at (a) Arnarbæli test site with $\mathrm{dx}=1 \mathrm{~m}$ and $x_{1}=10 \mathrm{~m}$ (2015 measurement), (d) Bakkafjara test site with $\mathrm{dx}=2 \mathrm{~m}$ and $x_{1}=15 \mathrm{~m}$, and $(g)$ Hella test site with $\mathrm{dx}=1 \mathrm{~m}$ and $x_{1}=10 \mathrm{~m}$. Dispersion image for $(b)$ Arnarbæli site, $(e)$ Bakkafjara site, and $(h)$ Hella site. Fundamental-mode dispersion curve and upper- and lower-bound curves for $(c)$ Arnarbæli site, $(f)$ Bakkafjara site, and (i) Hella site. [Colour online.]

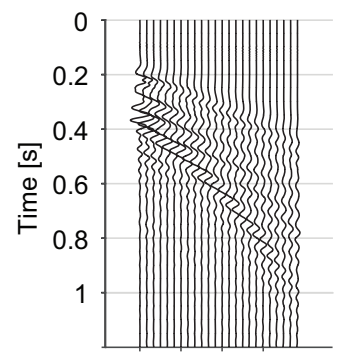

10162228

Distance from source $[\mathrm{m}]$

(a)

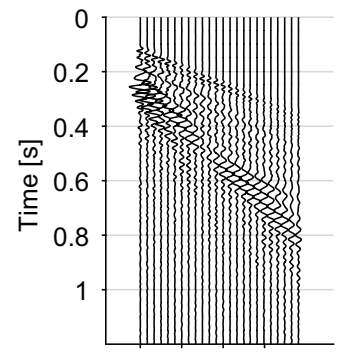

15273951

Distance from source $[\mathrm{m}]$

(d)

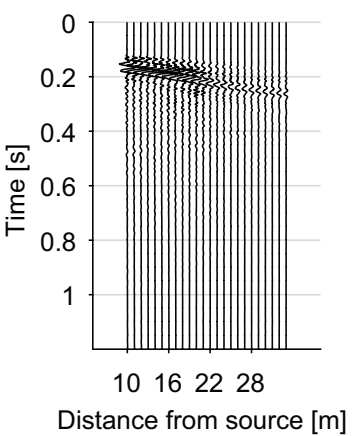

(g)

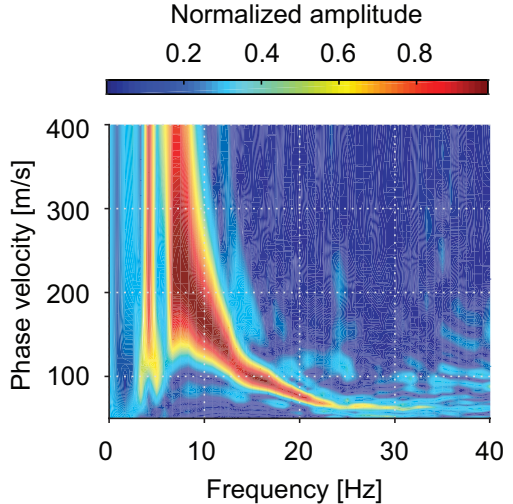

(b)

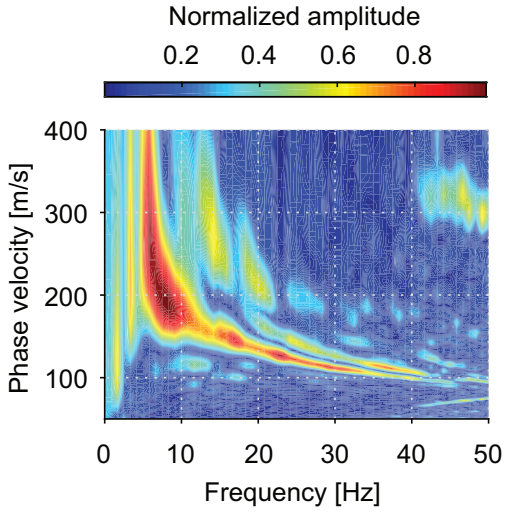

(e)

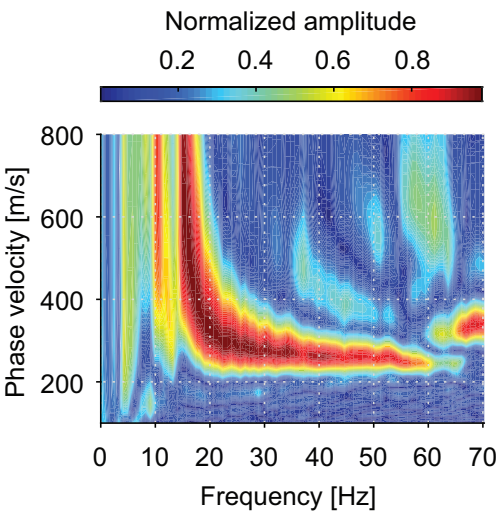

(h)

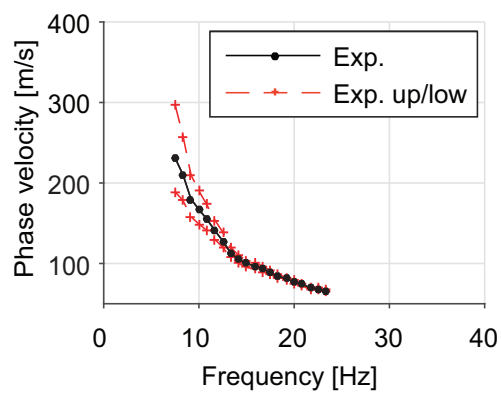

(c)

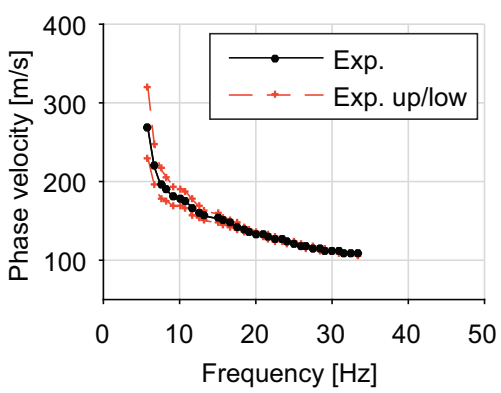

(f)

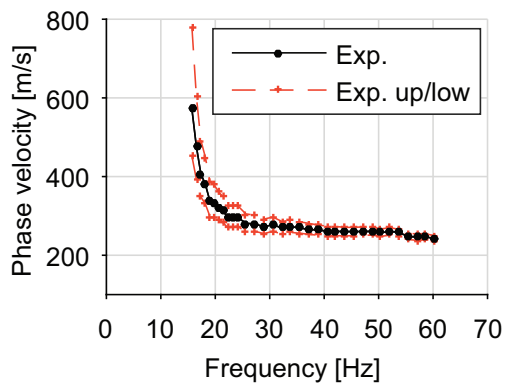

(i)

ing ratio of 0.5 . The geophones were connected to two data acquisition cards (NI USB-6218 from National Instruments, Austin, Texas) and a computer equipped with a customized multichannel data-acquisition software. A $6.3 \mathrm{~kg}$ sledgehammer was used as an impact source in all cases. A summary of the main parameters related to the field measurements is provided in Table 4.

Figures $13 a, 13 d$, and $13 g$ show velocity time series acquired at the test sites at Arnarbæli, Bakkafjara, and Hella, respectively. The corresponding dispersion images are provided in Figs. 13b, 13e, and $13 \mathrm{~h}$. The fundamental-mode dispersion curves that were extracted from the spectra are shown in Figs. 13c, 13f, and 13i, respec- tively. The frequency ranges at which the fundamental mode could be identified in each case are provided in Table 4 . The upperand lower-bound curves shown in Figs. 13c, 13f, and 13i correspond to $95 \%$ of the identified fundamental-mode peak spectral amplitude value $\left(A_{\mathrm{s} \text {,max }}\right)$ at each frequency.

It must be underlined that identification of the fundamentalmode dispersion curve is not a straightforward task in all cases. Irregularities in the suspected fundamental-mode high-amplitude band, e.g., abrupt bends or jumps to higher or lower phase velocities at certain frequencies, might indicate that the peak energy is not following the fundamental-mode over the entire frequency 
Fig. 14. (a) Comparison of experimental and theoretical dispersion curves for the Arnarbæli, Bakkafjara, and Hella test sites. (b) Estimated shear wave velocity profiles for the test sites. [Colour online.]

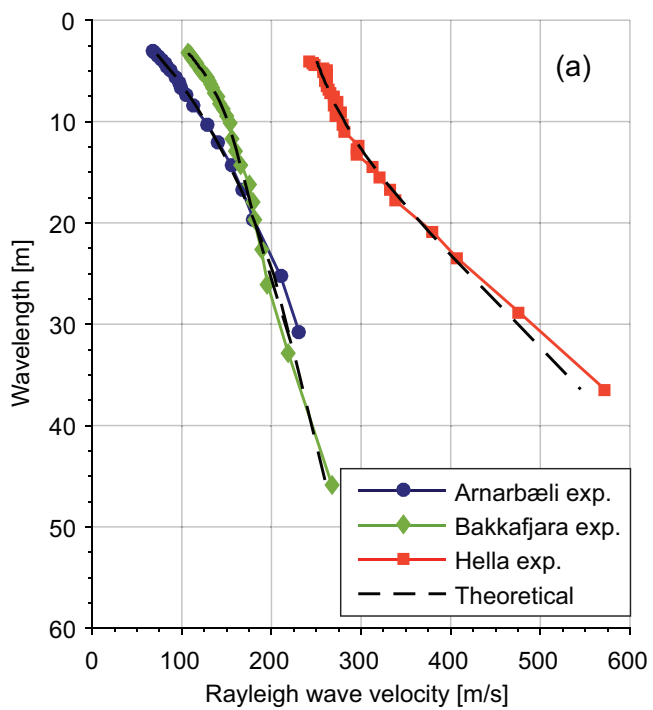

range (see also Fig. 4a). The dispersion images in Figs. 13b, 13e, and $13 \mathrm{~h}$, and the corresponding dispersion curves in Figs. 13c, 13f, and $13 i$ are based on a single surface wave record in each case. Relying on a dispersion curve identified based on a single record is not always advisable. Furthermore, the configuration of the measurement profile can have a substantial effect on the energy distribution represented in the dispersion image and consequently the uncertainty associated with the dispersion curve identification and extraction. Hence, based on the authors' experience, combined or repeated analysis of data acquired by using several different measurement profile configurations should be carried out to help confident identification of the fundamental-mode dispersion curve.

Results of the inversion analysis of the data acquired at the Arnarbæli, Bakkafjara, and Hella test sites are illustrated in Fig. 14. The misfit between the experimental dispersion curves observed at each site and the optimum theoretical curves (Fig. 14a), evaluated according to eq. (16), is in all cases less than $2 \%$. The timeaverage shear wave velocity of the uppermost $30 \mathrm{~m}$ at the three test sites and their corresponding soil classification group according to Eurocode 8 is provided in Table 4.

\section{Repeatability of the MASW analysis}

At the Arnarbæli test site, surface wave data were collected in three separate field tests in September 2013, August 2014, and July 2015. The test configuration, i.e., the number of receivers, the receiver spacing, and the source offset, was the same in all cases (see Table 4).

Figure 15a shows a comparison of experimental dispersion curves for the Arnarbæli test site, evaluated based on surface wave records acquired in 2013, 2014, and 2015. The upper- and lowerbound curves shown in Fig. 15a correspond to 95\% of the identified fundamental-mode peak spectral amplitude value at each frequency. The shear wave velocity profiles obtained by inversion of each experimental curve are provided in Fig. 15b. The shear wave velocity profiles are compared in terms of the time-average shear wave velocities of the uppermost $5,10,20$, and $30 \mathrm{~m}$ in Table 5 . The results provided in Fig. 15 and Table 5 indicate that the agreement between the three measurements is good, illustrating the consistency of the methodology and the software that has been developed.

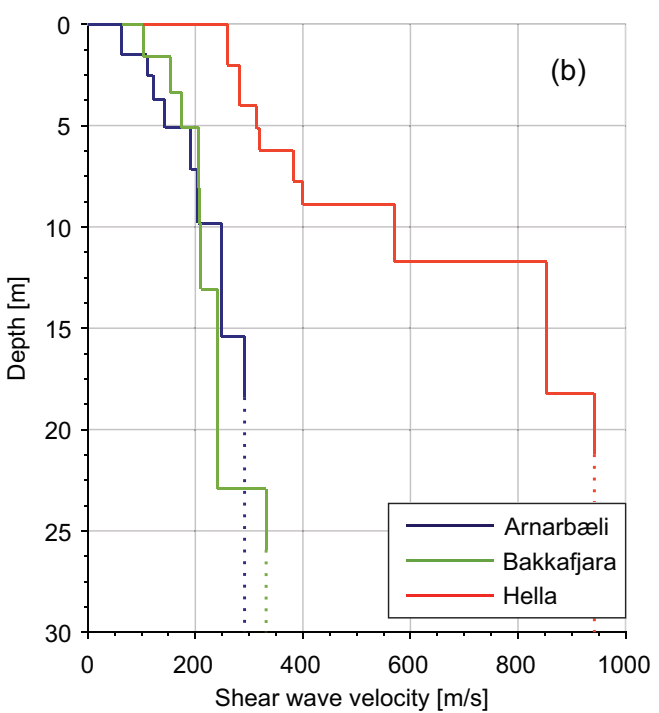

Comparison of MASW and SASW measurement results

SASW measurements were carried out in 2009 at Bakkafjara (Bessason and Erlingsson 2011) approximately $0.5 \mathrm{~km}$ east of the site where the MASW field data were acquired. Bakkafjara is a long sandy beach area that can be considered to be quite uniform.

Figure 16 shows comparison of the experimental dispersion curves estimated based on the 2009 SASW measurements and the 2014 MASW measurements. The SASW dispersion curve (SASW mean in Fig. 16) was obtained by adding up experimental dispersion curves computed for multiple receiver pairs within $1 / 3$ octave wavelength intervals. The upper- and lower-bound SASW dispersion curves correspond to plus-minus one standard deviation of the mean curve. The upper- and lower-bound MASW curves correspond to $95 \%$ of the identified fundamental-mode peak spectral amplitude value at each frequency. The results presented in Fig. 16 indicate that the SASW dispersion curve agrees well with the MASW dispersion curve.

\section{Conclusions}

This paper presents the first version of a new open-source software, MASWaves, for processing and analysing multichannel surface wave records using the MASW method. The software consists of two main parts: a tool for dispersion analysis (MASWaves Dispersion) and a tool for inversion analysis (MASWaves Inversion). The software can be downloaded free of charge along with a user guide and sample data at masw.hi.is.

The aim of the dispersion analysis is to identify and extract experimental Rayleigh wave dispersion curves from the recorded multichannel surface wave data. Computations are carried out utilizing the phase shift method (Park et al. 1998). The phase shift method provides visualization of the dispersion properties of all types of waves contained in the acquired data in the form of a twoor three-dimensional dispersion image (phase velocity spectra), from which the Rayleigh wave dispersion curve(s) are identified based on the spectral maxima. Upper and lower boundaries for the extracted dispersion curve(s) can be obtained and visualized in either the frequency-phase velocity or the phase velocity-wavelength domain. Experimental fundamental- and higher-mode dispersion curves obtained by MASWaves Dispersion were compared with results acquired using the open-source software Geopsy. The agreement of the estimated dispersion curves was in all cases good, confirming the precision of the new software and its ability 
Fig. 15. (a) Comparison of experimental dispersion curves for Arnarbæli test site acquired based on three separate field tests in September 2013, August 2014, and July 2015. (b) Comparison of shear wave velocity profiles for Arnarbæli test site evaluated based on data acquired in 2013, 2014, and 2015. [Colour online.]

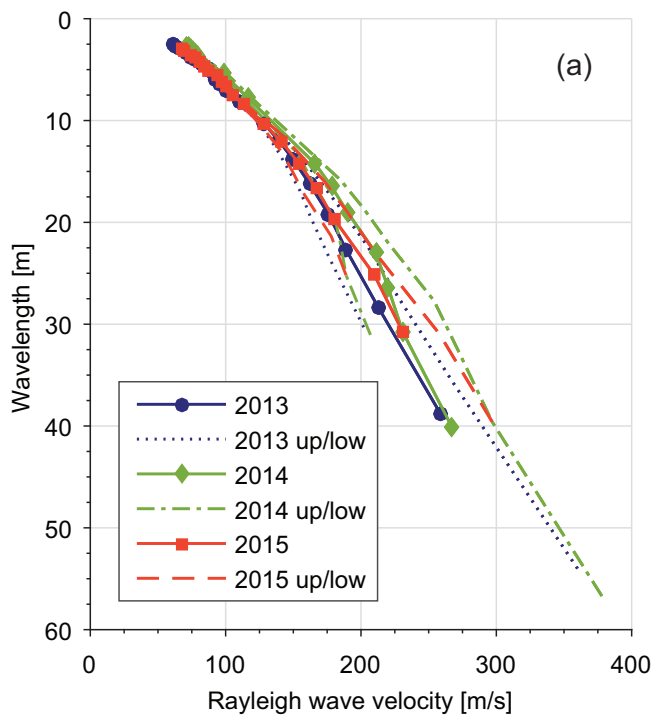

Table 5. Time-average shear wave velocity of the uppermost 5, 10, 20, and $30 \mathrm{~m}$ at the Arnarbæli test site evaluated based on data acquired in 2013, 2014, and 2015.

\begin{tabular}{lclll}
\hline $\begin{array}{l}\text { Year of data } \\
\text { acquisition }\end{array}$ & $V_{\mathrm{S}, 5}(\mathrm{~m} / \mathrm{s})$ & $V_{\mathrm{S}, 10}(\mathrm{~m} / \mathrm{s})$ & $V_{\mathrm{S}, 20}(\mathrm{~m} / \mathrm{s})$ & $V_{\mathrm{S}, 30}(\mathrm{~m} / \mathrm{s})$ \\
\hline 2013 & 94 & 128 & 175 & 211 \\
2014 & 103 & 137 & 182 & 214 \\
2015 & 96 & 129 & 176 & 204 \\
\hline
\end{tabular}

Fig. 16. Comparison of experimental dispersion curves obtained at Bakkafjara test site by the SASW and MASW methods. [Colour online.]

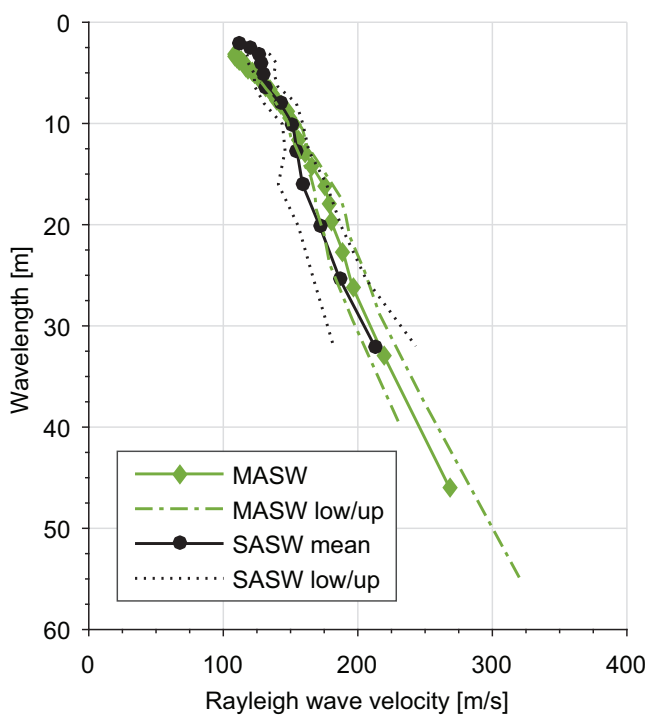

to separate fundamental- and higher-mode experimental dispersion curves.

Determination of the experimental Rayleigh wave dispersion curve is a critical stage in the application of MASW. The operator should be aware that the most obvious coherent high-amplitude band of the dispersion image cannot be assumed to provide the fundamental-mode dispersion curve in all cases. Due to the geol-

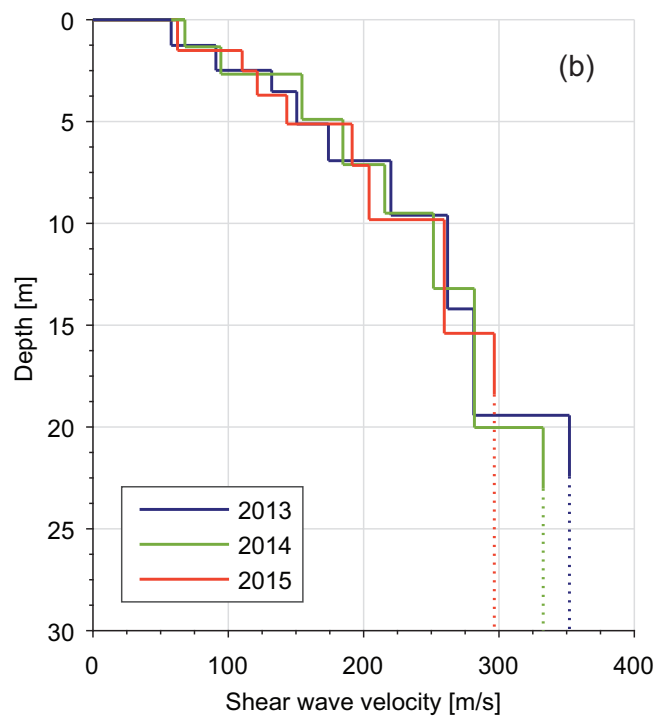

ogy of the test site (e.g., the presence of a stiff surface layer, a stiff layer sandwiched between two softer layers or abrupt increase in stiffness with depth), higher modes can play a significant role over certain frequency ranges, thus violating the fundamental-mode assumption. In such cases, misidentification of mode numbers and (or) superposition of dispersion data from multiple modes is likely to occur. Mistaking a higher mode or an apparent dispersion curve as the fundamental-mode dispersion curve can cause severe errors in the subsequent inversion analysis.

The configuration of the measurement profile has been shown to affect the resolution and the viable frequency range of the dispersion image. A longer receiver spread is, in general, preferable to improve the spectral resolution, but risks significant lateral variations along the geophone array, attenuation of higherfrequency surface wave components, and spatial aliasing. Hence, based on the authors' experience, combined or repeated analysis of data acquired by using several different measurement profile configurations can help in correctly identifying the fundamentalmode dispersion curve without reducing the investigation depth range of the survey.

The inversion analysis involves obtaining a shear wave velocity profile by inversion of the experimental fundamental-mode dispersion curve, assuming a plane-layered elastic earth model. The inversion analysis tool, MASWaves Inversion, consists of two main components. First, a mathematical model to compute theoretical dispersion curves using the stiffness matrix method of Kausel and Roësset (1981) and, second, an algorithm to evaluate the misfit between the experimental and theoretical curves and to allow the user to update the set of model parameters. The theoretical dispersion curve computations of MASWaves Inversion were validated by comparison to results obtained by the software WinSASW (version 1.2) and results presented by Tokimatsu et al. (1992) and Tokimatsu (1997).

However, the inverse problem faced in the inversion analysis is inherently nonunique, i.e., multiple drastically different shear wave velocity profiles can provide theoretical dispersion curves that correspond similarly well to the experimental curve. An unsuitable layering parameterization can result in an "optimal" shear wave velocity profile that does not realistically represent the subsurface conditions. To minimize the potentially adverse effect of the layering parameterization and, hence, increase the potential of obtaining a realistic shear wave velocity profile, in- 
vestigating multiple different parameterizations during the inversion analysis is recommended (Cox and Teague 2016).

The new software has been used to obtain site-specific shear wave velocity profiles based on MASW field data acquired at three sites with different stiffness characteristics in south Iceland: Arnarbæli, Bakkafjara, and Hella. At the Arnarbæli test site, data were collected in three separate field test campaigns to confirm the repeatability of the analysis and the consistency of the new software. The agreement between the three measurements was good. Moreover, the results of the MASW analysis at Bakkafjara were compared with results of SASW measurements previously carried out at the site. Good agreement between the SASW and the MASW dispersion curves was observed, further validating the performance of the dispersion analysis tool.

\section{Acknowledgements}

The project has been supported financially by grants from the University of Iceland Research Fund, the Icelandic Road and Coastal Administration, and the Energy Research Fund of the National Power Company of Iceland.

\section{References}

Abo-Zena, A. 1979. Dispersion function computations for unlimited frequency values. Geophysical Journal of the Royal Astronomical Society, 58(1): 91-105. doi:10.1111/j.1365-246X.1979.tb01011.x.

Aki, K., and Richards, P.G. 1980. Quantitative seismology: theory and methods. Vol. 1. W.H. Freeman and Co., San Francisco, Calif.

Asten, M.W. 2006. On bias and noise in passive seismic data from finite circular array data processed using SPAC methods. Geophysics, 71(6): V153-V162. doi: $10.1190 / 1.2345054$

Bessason, B., and Erlingsson, S. 2011. Shear wave velocity in surface sediments. Jökull, 61: 51-64.

Buchen, P.W., and Ben-Hador, R. 1996. Free-mode surface-wave computations. Geophysical Journal International, 124(3): 869-887. doi:10.1111/j.1365-246X. 1996.tb05642.x.

CEN. 2004. Eurocode 8: Design of structures for earthquake resistance - Part 1: General rules, seismic actions and rules for buildings. European Committee for Standardization (CEN), Brussels, Belgium.

Cox, B.R., and Teague, D.P. 2016. Layering ratios: a systematic approach to the inversion of surface wave data in the absence of a priori information. Geophysical Journal International, 207: 422-438. doi:10.1093/gji/ggw282.

Dal Moro, G., Pipan, M., Forte, E., and Finetti, I. 2003. Determination of Rayleigh wave dispersion curves for near surface applications in unconsolidated sediments. In SEG Technical Program Expanded Abstracts of the Society of Exploration Geophysicists (SEG) International Exposition and 73rd Annual Meeting, Dallas, Tex., 26-31 October 2003. Society of Exploration Geophysicists, Tulsa, Okla. pp. 1247-1250. doi:10.1190/1.1817508.

Di Giulio, G., Cornou, C., Ohrnberger, M., Wathelet, M. and Rovelli, A. 2006. Deriving wavefield characteristics and shear-velocity profiles from twodimensional small-aperture arrays analysis of ambient vibrations in a smallsize alluvial basin, Colfiorito, Italy. Bulletin of the Seismological Society of America, 96(5): 1915-1933. doi:10.1785/0120060119.

Di Giulio, G., Savvaidis, A., Ohrnberger, M., Wathelet, M., Cornou, C., Knapmeyer-Endrun, B., Renalier, F., Theodoulidis, N., and Bard, P.Y. 2012. Exploring the model space and ranking a best class of models in surface-wave dispersion inversion: Application at European strong-motion sites. Geophysics, 77: B147-B166. doi:10.1190/geo2011-0116.1.

Foti, S., Lai, C.G., Rix, G.J., and Strobbia, C. 2015. Surface wave methods for near-surface site characterization. CRC Press, Taylor \& Francis Group, Boca Raton, Fla.

Gao, L., Xia, J., Pan, Y., and Xu, Y. 2016. Reason and Condition for Mode Kissing in MASW Method. Pure and Applied Geophysics, 173(5): 1627-1638. doi:10.1007| s00024-015-1208-5.

Garofalo, F., Foti, S., Hollender, F., Bard, P.-Y., Cornou, C., Cox, B.R., Ohrnberger, M., Sicilia, D., Asten, M., et al. 2016. InterPACIFIC project: comparison of invasive and non-invasive methods for seismic site characterization. Part I: Intra-comparison of surface wave methods. Soil Dynamics and Earthquake Engineering, 82: 222-240. doi:10.1016/j.soildyn.2015.12.010.

Gazetas, G. 1991. Foundation vibrations. In Foundation engineering handbook. Edited by H.-Y. Fang. Van Nostrand Reinhold, New York. pp. 553-593.

Gouveia, F., Lopes, I., and Gomes, R.C. 2016. Deeper $V_{S}$ profile from joint analysis of Rayleigh wave data. Engineering Geology, 202: 85-98. doi:10.1016/j.enggeo. 2016.01.006

Green, R.A., Halldorsson, B., Kurtulus, A., Steinarsson, H., and Erlendsson, O. 2012. A unique liquefaction case study from the 29 May 2008, $M_{w} 6.3$ Olfus earthquake, southwest Iceland. In Proceedings of the 15th World Conference on Earthquake Engineering, Lisbon, Portugal, 24-28 September 2012. The Portuguese Earthquake Engineering Community, Lisbon, Portugal.
Gucunski, N., and Woods, R.D. 1991. Use of Rayleigh Modes in interpretation of SASW test. In Proceedings of the Second International Conference on Recent Advances in Geotechnical Earthquake Engineering and Soil Dynamics, St. Louis, Mo., 11-15 March 1991. Paper No. 10.10.

Haskell, N.A. 1953. The dispersion of surface waves on multilayered media. Bulletin of the Seismological Society of America, 43(1): 17-34

Hobiger, M., Bard, P.-Y., Cornou, C., and Le Bihan, N. 2009. Single station determination of Rayleigh wave ellipticity by using the random decrement technique (RayDec). Geophysical Research Letters, 36: L14303. doi:10.1029/ 2009GL038863.

Hobiger, M., Cornou, C., Wathelet, M., Di Giulio, G., Knapmeyer-Endrun, B., Renalier, F., Bard, P.-Y., Savvaidis, A., Hailemikael, S., et al. 2013. Ground structure imaging by inversions of Rayleigh wave ellipticity: sensitivity analysis and application to European strong-motion sites. Geophysical Journal International, 192(1): 207-229. doi:10.1093/gji/ggs005.

Ivanov, J., Miller, R.D., and Tsoflias, G. 2008. Some practical aspects of MASW analysis and processing. In Proceedings of the 21st EEGC Symposium on the Application of Geophysics to Engineering and Environmental Problems, Philadelphia, Pa., 6-10 April 2008. pp. 1186-1198.

Kausel, E., and Roësset, J.M. 1981. Stiffness matrices for layered soils. Bulletin of the Seismological Society of America, 71(6): 1743-1761.

Kennett, B.L.N. 1974. Reflections, rays, and reverberations. Bulletin of the Seismological Society of America, 64(6): 1685-1696.

Kennett, B.L.N., and Kerry, N.J. 1979. Seismic waves in a stratified half space. Geophysical Journal International, 57(3): 557-583. doi:10.1111/j.1365-246X.1979. tb06779.x.

Knopoff, L. 1964. A matrix method for elastic wave problems. Bulletin of the Seismological Society of America, 54(1): 431-438.

Kramer, S.L. 1996. Geotechnical Earthquake Engineering. Prentice-Hall, Inc., Upper Saddle River, N.J.

Louie, J.N. 2001. Faster, better: shear-wave velocity to 100 meters depth from refraction microtremor arrays. Bulletin of the Seismological Society of America, 91(2): 347-364. doi:10.1785/0120000098.

McMechan, G.A., and Yedlin, M.J. 1981. Analysis of dispersive waves by wave field transformation. Geophysics, 46(6): 869-874. doi:10.1190/1.1441225.

Menke, W. 1979. Comment on 'Dispersion function computations for unlimited frequency values' by Anas Abo-Zena. Geophysical Journal of the Royal Astronomical Society, 59(2): 315-323. doi:10.1111/j.1365-246X.1979.tb06769.x.

Nazarian, S., Stokoe, K.H., II, and Hudson, W.R. 1983. Use of spectral analysis of surface waves method for determination of moduli and thicknesses of pavement systems. Transportation Research Record, 930: 38-45.

Olafsdottir, E.A. 2016. Multichannel analysis of surface waves for assessing soil stiffness. M.Sc. thesis, Faculty of Civil and Environmental Engineering, University of Iceland, Reykjavík, Iceland. Available from http://hdl.handle.net/ $1946 / 23646$.

Olafsdottir, E.A., Bessason, B., and Erlingsson, S. 2015. MASW for assessing liquefaction of loose sites. In Proceedings of the 16th European Conference on Soil Mechanics and Geotechnical Engineering, Edinburgh, UK, 13-17 September 2015. ICE Publishing, London, UK. pp. 2431-2436.

Olafsdottir, E.A., Erlingsson, S., and Bessason, B. 2016. Effects of measurement profile configuration on estimation of stiffness profiles of loose post glacial sites using MASW. In Proceedings of the 17th Nordic Geotechnical Meeting, Reykjavik, Iceland, 25-28 May 2016. The Icelandic Geotechnical Society, Reykjavik, Iceland. pp. 327-336.

Park, C.B. 2011. Imaging dispersion of MASW data - full vs. selective offset scheme. Journal of Environmental and Engineering Geophysics, 16(1): 13-23. doi:10.2113/JEEG16.1.13.

Park, C.B., and Carnevale, M. 2010. Optimum MASW survey-revisit after a decade of use. In Proceedings of GeoFlorida 2010: Advances in Analysis, Modeling \& Design, Geo-Institute Annual Meeting Conference Proceedings, West Palm Beach, Fla., 20-24 February 2010. American Society of Civil Engineers, Reston, Va. pp. 1303-1312. doi:10.1061/41095(365)130.

Park, C.B., and Miller, R.D. 2008. Roadside passive multichannel analysis of surface waves (MASW). Journal of Environmental \& Engineering Geophysics, 13(1): 1-11. doi:10.2113/JEEG13.1.1.

Park, C.B., Miller, R.D., and Xia, J. 1998. Imaging dispersion curves of surface waves on multi-channel record. In SEG Technical Program Expanded Abstracts of the Society of Exploration Geophysicists (SEG) International Exposition and 68th Annual Meeting, New Orleans, La., 13-18 September 1998. Society of Exploration Geophysicists, Tulsa, Okla., pp. 1377-1380. doi:10.1190/1.1820161.

Park, C.B., Miller, R.D., and Xia, J. 1999. Multichannel analysis of surface waves. Geophysics, 64(3): 800-808. doi:10.1190/1.1444590.

Park, C.B., Miller, R.D., and Miura, H. 2002. Optimum field parameters of an MASW survey. [Expanded abstract.] In Proceedings of the 6th SEG-J International Symposium, Tokyo, Japan, 22-23 May 2002.

Park, C.B., Miller, R.D., Rydén, N., Xia, J., and Ivanov, J. 2005. Combined use of active and passive surface waves. Journal of Environmental and Engineering Geophysics, 10(3): 323-334. doi:10.2113/JEEG10.3.323.

Park, C.B., Miller, R.D., Xia, J., and Ivanov, J. 2007. Multichannel analysis of surface waves (MASW)-active and passive methods. The Leading Edge, 26(1): 60-64. doi:10.1190/1.2431832.

Ryden, N., Park, C.B., Ulriksen, P., and Miller, R.D. 2004. Multimodal approach to 
seismic pavement testing. Journal of Geotechnical and Geoenvironmental Engineering, 130(6): 636-645. doi:10.1061/(ASCE)1090-0241(2004)130:6(636).

Schwab, F. 1970. Surface-wave dispersion computations: Knopoff's method. Bulletin of the Seismological Society of America, 60(5): 1491-1520.

Socco, L.V., Foti, S., and Boiero, D. 2010. Surface-wave analysis for building near-surface velocity models - established approaches and new perspectives. Geophysics, 75(5): 75A83-75A102. doi:10.1190/1.3479491.

Thomson, W.T. 1950. Transmission of elastic waves through a stratified solid medium. Journal of Applied Physics, 21(2): 89-93. doi:10.1063/1.1699629.

Tokimatsu, K. 1997. Geotechnical site characterization using surface waves. In Proceedings of IS-Tokyo, the First International Conference on Earthquake Geotechnical Engineering, Tokyo, Japan, 14-16 November 1995. Balkema, Rotterdam, the Netherlands. Vol. 3, pp. 1333-1368.

Tokimatsu, K., Tamura, S., and Kojima, H. 1992. Effects of multiple modes on Rayleigh wave dispersion characteristics. Journal of Geotechnical Engineering, 118(10): 1529-1543. doi:10.1061/(ASCE)0733-9410(1992)118:10(1529).

UTAustin. 1992. WinSASW. Data reduction program for Spectral-Analysis-ofSurface-Wave (SASW) tests. Ver. 1.2. User's guide. The University of Texas at Austin (UTAustin), Austin, Tex.

Wathelet, M., Jongmans, D., Ohrnberger, M., and Bonnefoy-Claudet, S. 2008. Array performances for ambient vibrations on a shallow structure and consequences over $\mathrm{V}_{\mathrm{S}}$ inversion. Journal of Seismology, 12(1): 1-19. doi:10.1007| s10950-007-9067-x.

Xia, J. 2014. Estimation of near-surface shear-wave velocities and quality factors using multichannel analysis of surface-wave methods. Journal of Applied Geophysics, 10: 140-151. doi:10.1016/j.jappgeo.2014.01.016.

Xia, J., Miller, R.D., and Park, C.B. 1999. Estimation of near-surface shear-wave velocity by inversion of Rayleigh waves. Geophysics, 64(3): 691-700. doi:10. 1190/1.1444578.

Xia, J., Miller, R.D., Park, C.B., Hunter, J.A., Harris, J.B., and Ivanov, J. 2002. Comparing shear-wave velocity profiles inverted from multichannel surface wave with borehole measurements. Soil Dynamics and Earthquake Engineering, 22(3): 181-190. doi:10.1016/S0267-7261(02)00008-8.

Xia, J., Miller, R.D., Park, C.B., and Tian, G. 2003. Inversion of high frequency surface waves with fundamental and higher modes. Journal of Applied Geophysics, 52(1): 45-57. doi:10.1016/S0926-9851(02)00239-2.

Xia, J., Xu, Y., and Miller, R.D. 2007. Generating an image of dispersive energy by frequency decomposition and slant stacking. Pure and Applied Geophysics, 164(5): 941-956. doi:10.1007/s00024-007-0204-9.

Yilmaz, Ö. 1987. Seismic data processing. Society of Exploration Geophysicists, Tulsa, Okla.

Yoon, S., and Rix, G.J. 2009. Near-field effects on array-based surface wave methods with active sources. Journal of Geotechnical and Geoenvironmental Engineering, 135(3): 399-406. doi:10.1061/(ASCE)1090-0241(2009)135:3(399).

Zhang, S.X., and Chan, L.S. 2003. Possible effects of misidentified mode number on Rayleigh wave inversion. Journal of Applied Geophysics, 53(1): 17-29. doi: 10.1016/S0926-9851(03)00014-4.

\section{List of symbols}

$A_{j}(\omega)$ amplitude spectrum of $\tilde{u}\left(x_{j}, \omega\right)$

$A_{\mathrm{s}}$ summed (slant-stacked) amplitude

$A_{\mathrm{s}, \max }$ maximum summed (slant-stacked) amplitude

a user-defined coefficient

$c$ Rayleigh wave phase velocity

$c_{\mathrm{e}, q}$ experimental Rayleigh wave phase velocity

$c_{\mathrm{T}}$ testing Rayleigh wave phase velocity

$c_{\mathrm{T}, \min }, c_{\mathrm{T}, \max }$ minimum and maximum Rayleigh wave testing phase velocities

$c_{\mathrm{t}, q}$ theoretical Rayleigh wave phase velocity

$c(\omega)$ Rayleigh wave phase velocity at frequency $\omega$

d depth

$\mathrm{dx}$ receiver spacing

$F_{R}$ dispersion function

$f$ frequency

$f_{\mathrm{s}}$ sampling rate

$G_{\max }$ small-strain shear modulus

$h$ layer thickness

$h_{j}$ thickness of $j$ th layer

$i i^{2}=-1$

$j, q$ indices

K system stiffness matrix

$\mathbf{K}_{\mathbf{e}, j}$ element stiffness matrix of $j$ th layer

$k$ wave number

$k_{\mathrm{t}, q}$ theoretical Rayleigh wave wave number

$L$ length of receiver spread

$L_{T}$ length of measurement profile

$M$ number of layers from the surface to depth $d$

$N$ number of receivers $n$ number of finite thickness layers

$p$ slowness

$\boldsymbol{p}$ system external load vector

$p_{\mathrm{A}}$ percentage

$\boldsymbol{p}_{\mathrm{e}, j}$ element external load vector of $j$ th layer

$Q$ number of data points in an experimental dispersion curve

$T$ recording time

$t$ time

$\boldsymbol{u}$ system displacement vector

$\boldsymbol{u}_{\mathrm{e}, j}$ element displacement vector of $j$ th layer

$u\left(x_{j}, t\right)$ multichannel surface wave record

$\tilde{u}\left(x_{j}, \omega\right)$ Fourier transformed multichannel surface wave record

$\tilde{u}_{\text {norm }}\left(x_{j}, \omega\right)$ Fourier transformed multichannel surface wave record normalized in the offset and frequency dimensions

$V_{\mathrm{S}, d}$ time-average shear wave velocity of the uppermost $d$ metres

$x$ horizontal coordinate

$x_{1}$ source offset

$x_{j}$ distance from the impact load point to receiver $j$

$z$ vertical coordinate

$z_{j} \quad z$-coordinate at the top of $j$ th layer

$z_{j+1} \quad z$-coordinate at the bottom of $j$ th layer

$z_{\max }$ maximum investigation depth

$\alpha$ compressional wave velocity

$\alpha_{j}$ compressional wave velocity of $j$ th layer

$\beta$ shear wave velocity

$\beta_{j}$ shear wave velocity of $j$ th layer

$\Delta c_{\mathrm{T}}$ testing phase velocity increment

$\epsilon$ misfit

$\epsilon_{\max }$ maximum misfit

$\lambda$ wavelength

$\lambda_{\mathrm{e}, q}$ experimental Rayleigh wave wavelength

$\lambda_{\max }$ maximum wavelength

$\lambda_{\mathrm{t}, q}$ theoretical Rayleigh wave wavelength

$\nu$ Poisson's ratio

$\nu_{j}$ Poisson's ratio of $j$ th layer

$\rho$ mass density

$\rho_{j}$ mass density of $j$ th layer

$\rho_{\text {sat }}$ saturated mass density

$\Phi_{j}(\omega)$ phase spectrum of $\tilde{u}\left(x_{j}, \omega\right)$

$\Phi_{\mathrm{T}, j}$ testing angular wave number

$\omega$ angular frequency

\section{Appendix A. Stiffness matrix method}

The components of the element stiffness matrix $\mathbf{K}_{\mathbf{e}, j}$ for layers $j=1, \ldots, n$ are

$\kappa_{11, j}=\frac{k \rho_{j} c^{2}}{D_{j}}\left[s_{j}^{-1} \cosh \left(k r_{j} h_{j}\right) \sinh \left(k s_{j} h_{j}\right)-r_{j} \sinh \left(k r_{j} h_{j}\right) \cosh \left(k s_{j} h_{j}\right)\right]$

$\kappa_{12, j}=\frac{k \rho_{j} c^{2}}{D_{j}}\left[\cosh \left(k r_{j} h_{j}\right) \cosh \left(k s_{j} h_{j}\right)-r_{j} s_{j} \sinh \left(k r_{j} h_{j}\right) \sinh \left(k s_{j} h_{j}\right)-1\right]$

$\kappa_{13, j}=\frac{k \rho_{j} c^{2}}{D_{j}}\left[r_{j} \sinh \left(k r_{j} h_{j}\right)-s_{j}^{-1} \sinh \left(k s_{j} h_{j}\right)\right]$

$-k \rho_{j} \beta_{j}^{2}\left(1+s_{j}^{2}\right)$

$\kappa_{14, j}=\frac{k \rho_{j} c^{2}}{D_{j}}\left[-\cosh \left(k r_{j} h_{j}\right)+\cosh \left(k s_{j} h_{j}\right)\right]$

$\kappa_{21, j}=\kappa_{12, j}$

$\kappa_{22, j}=\frac{k \rho_{j} c^{2}}{D_{j}}\left[r_{j}^{-1} \sinh \left(k r_{j} h_{j}\right) \cosh \left(k s_{j} h_{j}\right)-s_{j} \cosh \left(k r_{j} h_{j}\right) \sinh \left(k s_{j} h_{j}\right)\right]$

$\kappa_{23, j}=-\kappa_{14, j}$

$\kappa_{24, j}=\frac{k \rho_{j} c^{2}}{D_{j}}\left[-r_{j}^{-1} \sinh \left(k r_{j} h_{j}\right)+s_{j} \sinh \left(k s_{j} h_{j}\right)\right]$

$\kappa_{31, j}=\kappa_{13, j}$

$\kappa_{32, j}=\kappa_{23, j}=-\kappa_{14, j}$

$\kappa_{33, j}=\kappa_{11, j}$

$\kappa_{34, j}=-\kappa_{12, j}$

$\kappa_{41, j}=\kappa_{14}$

$\kappa_{42, j}=\kappa_{24, j}$

$\kappa_{43, j}=-\kappa_{21, j}=-\kappa_{12, j}$

$\kappa_{44, j}=\kappa_{22, j}$ 
where $r_{j}$ and $s_{j}$ are obtained as

$$
r_{j}=\sqrt{1-\frac{c^{2}}{\alpha_{j}^{2}}} \text { and } s_{j}=\sqrt{1-\frac{c^{2}}{\beta_{j}^{2}}}
$$

and

$$
\begin{aligned}
D_{j}=2\left[1-\cosh \left(k r_{j} h_{j}\right) \cosh \left(k s_{j} h_{j}\right)\right] & \\
& +\left(\frac{1}{r_{j} s_{j}}+r_{j} s_{j}\right) \sinh \left(k r_{j} h_{j}\right) \sinh \left(k s_{j} h_{j}\right)
\end{aligned}
$$

The components of the half-space element stiffness matrix $\mathbf{K}_{e, n+1}$ are

$$
\begin{aligned}
& \kappa_{11, n+1}=k \rho_{n+1} \beta_{n+1}^{2} \frac{r_{n+1}\left(1-s_{n+1}^{2}\right)}{1-r_{n+1} s_{n+1}} \\
& \kappa_{12, n+1}=k \rho_{n+1} \beta_{n+1}^{2} \frac{1-s_{n+1}^{2}}{1-r_{n+1} s_{n+1}}-2 k \rho_{n+1} \beta_{n+1}^{2} \\
& \kappa_{21, n+1}=\kappa_{12, n+1} \\
& \kappa_{22, n+1}=k \rho_{n+1} \beta_{n+1}^{2} \frac{s_{n+1}\left(1-s_{n+1}^{2}\right)}{1-r_{n+1} s_{n+1}}
\end{aligned}
$$

The system stiffness matrix $\mathbf{K}$ is assembled from the element stiffness matrices at the common layer interfaces, i.e.,

$$
\mathbf{K}=\left[\begin{array}{llllll}
\mathbf{K}_{11,1} & \mathbf{K}_{12,1} & & & & \\
\mathbf{K}_{21,1} & \mathbf{K}_{22,1}+\mathbf{K}_{11,2} & \mathbf{K}_{12,2} & & & \\
& \mathbf{K}_{21,2} & \mathbf{K}_{22,2}+\mathbf{K}_{11,3} & \mathbf{K}_{12,3} & & \\
& & \ddots & \ddots & \ddots & \\
& & & \mathbf{K}_{21, n-1} & \mathbf{K}_{22, n-1}+\mathbf{K}_{11, n} & \mathbf{K}_{12, n} \\
& & & & \mathbf{K}_{21, n} & \mathbf{K}_{22, n}+\mathbf{K}_{\mathrm{e}, n+1}
\end{array}\right]
$$

where $\mathbf{K}_{11, j}, \mathbf{K}_{12, j}, \mathbf{K}_{21, j}$, and $\mathbf{K}_{22, j}$ are the $2 \times 2$ submatrices of the element stiffness matrix for the $j$ th layer

$$
\mathbf{K}_{e, j}=\left[\begin{array}{ll}
\mathbf{K}_{11, j} & \mathbf{K}_{12, j} \\
\mathbf{K}_{21, j} & \mathbf{K}_{22, j}
\end{array}\right]=\left[\begin{array}{llll}
\kappa_{11, j} & \kappa_{12, j} & \kappa_{13, j} & \kappa_{14, j} \\
\kappa_{21, j} & \kappa_{22, j} & \kappa_{23, j} & \kappa_{24, j} \\
\kappa_{31, j} & \kappa_{32, j} & \kappa_{33, j} & \kappa_{34, j} \\
\kappa_{41, j} & \kappa_{42, j} & \kappa_{43, j} & \kappa_{44, j}
\end{array}\right] \quad j=1, \ldots, n
$$

and $\mathbf{K}_{\mathrm{e}, n+1}$ is the $2 \times 2$ half-space element stiffness matrix

$$
\mathbf{K}_{\mathrm{e}, n+1}=\left[\begin{array}{ll}
\kappa_{11, n+1} & \kappa_{12, n+1} \\
\kappa_{21, n+1} & \kappa_{22, n+1}
\end{array}\right]
$$

\section{List of symbols}

$c$ Rayleigh wave phase velocity

$D_{j}$ parameter used for computation of the element stiffness matrix of $j$ th layer

$h_{j}$ thickness of $j$ th layer

$j$ index

K system stiffness matrix

$\mathbf{K}_{11, j} \mathbf{K}_{\mathrm{e}, j}$ element stiffness matrix of $j$ th layer

$\mathbf{K}_{11, j} \mathbf{K}_{12, j}$ submatrices of the element stiffness matrix of $j$ th layer

$\mathbf{K}_{21, j} \quad \mathbf{K}_{22, j}$ wave number

$n$ number of finite thickness layers

$r_{j} \sqrt{1-c^{2} / \alpha_{j}^{2}}$

$s_{j} \sqrt{1-c^{2} / \beta_{j}^{2}}$

$\alpha_{j}$ compressional wave velocity of $j$ th layer

$\beta_{j}$ shear wave velocity of $j$ th layer

$\kappa_{l m, j}$ components of the element stiffness matrix of $j$ th layer $\rho_{j}$ mass density of $j$ th layer 